\title{
Regulation of A-Kinase Anchoring Protein 79/150-cAMP-Dependent Protein Kinase Postsynaptic Targeting by NMDA Receptor Activation of Calcineurin and Remodeling of Dendritic Actin
}

\author{
Lisa. L. Gomez, ${ }^{1}$ Shuvo Alam, ${ }^{1}$ Karen E. Smith, ${ }^{1}$ Eric Horne, ${ }^{1}$ and Mark L. Dell'Acqua ${ }^{1,2}$ \\ ${ }^{1}$ Department of Pharmacology, ${ }^{2}$ Program in Neuroscience, University of Colorado Health Sciences Center, Denver, \\ Colorado 80262
}

At the postsynaptic membrane of glutamatergic synapses, the cAMP-dependent protein kinase (PKA), protein kinase $C(P K C)$, and calcineurin (CaN) anchoring protein AKAP79/150 is recruited to NMDA and AMPA glutamate receptors by postsynaptic density (PSD)-95 family membrane-associated guanylate kinase (MAGUK) scaffold proteins. These signaling scaffold complexes may function to regulate receptor phosphorylation in synaptic plasticity. Thus, it is important to understand regulation of AKAP79/150 targeting to synapses and recruitment to PSD-MAGUK complexes. AKAP79 is targeted to the plasma membrane by an $\mathrm{N}$-terminal basic domain that binds phosphatidylinositol-4,5-bisphosphate $\left(\mathrm{PI}-4,5-\mathrm{P}_{2}\right)$ and is regulated by PKC phosphorylation and calmodulin binding. Here we demonstrate that this same domain also binds F-actin in a calmodulin- and PKC-regulated manner, targets to membrane ruffles enriched in F-actin and $\mathrm{PI}-4,5-\mathrm{P}_{2}$ in COS7 cells, and localizes to dendritic spines with F-actin and PSD-MAGUKs in hippocampal neurons. Inhibition of actin polymerization disrupted AKAP79 targeting of PKA and CaN to ruffles in COS7 cells and endogenous AKAP79/150 dendritic spine localization with PKA, CaN, and PSD-MAGUKs in neurons. AKAP79/150 postsynaptic localization was rapidly regulated by NMDA receptors through $\mathrm{CaN}$ activation and F-actin remodeling, further suggesting that AKAP79/150 signaling scaffold targeting depends on actin dynamics. NMDA receptor activation also regulated dendritic spine localization of PKA and CaN and association of the AKAP79/150-PKA complex with PSD-MAGUKs. Because AMPA receptor PKA phosphorylation and synaptic localization are regulated by similar NMDA receptor-CaN signaling pathways linked to hippocampal long-term depression, this regulation of AKAP79/150 postsynaptic targeting might be important for synaptic plasticity.

Key words: postsynaptic density; actin; PSD-95 MAGUKs; AKAPs; PKA; calcineurin; NMDA and AMPA receptors
NMDA and AMPA glutamate receptors form complexes with cytoskeletal and scaffold proteins in the postsynaptic density (PSD) (Kennedy, 1997; Ziff, 1997). Prominent among these scaffolds are PSD-95 family membrane-associated guanylate kinases (PSD-MAGUKs) containing postsynaptic density-95, discs large, zona occludens-1 (PDZ), Src homology-3 (SH3), and guanylate kinase (GK) domains. Through binding MAGUKs and additional proteins, receptors are linked to intracellular signaling pathways and the actin cytoskeleton (Sheng and Scala, 2001). It is believed that regulation of this molecular architecture is essential for controlling glutamate receptors in hippocampal long-term potentiation (LTP) and long-term depression (LTD) synaptic plasticity (Luscher et al., 2000; Tomita et al., 2001).

Recent studies have shown that AMPA receptors are rapidly recruited to synapses by exocytosis during NMDA receptor-

Received March 28, 2002; revised May 10, 2002; accepted May 31, 2002.

This work was supported by grants to M.L.D. from the American Heart Association $(0130228 \mathrm{~N})$ and National Institutes of Health/National Institute of Neurological Disorders and Stroke (NS40701). We thank Dr. Yvonne Lai (ICOS, Bothel, WA) for AKAP79 and AKAP150 antibodies, and Ed Tall and Dr. Mario Rebecchi (State University of New York, Stonybrook, NY) for PLC $\delta$-PH-GFP. We also express our appreciation to Drs. Marcie Colledge and John D. Scott (Howard Hughes Medical Institute, Vollum Institute) for providing advice during this work. We appreciate the efforts of Drs. Michael Browning, Paula Hoffman (University of Colorado Health Sciences Center), and Reed C. Carroll (Albert Einstein College of Medicine) for critically reading this manuscript prior to submission.

Correspondence should be addressed to Mark L. Dell'Acqua, Department of Pharmacology, C-236, University of Colorado Health Sciences Center, 4200 East Ninth Avenue, Denver, CO 80262. E-mail: Mark.DellAcqua@uchsc.edu. Copyright (ㄷ) 2002 Society for Neuroscience $0270-6474 / 02 / 227027-18 \$ 15.00 / 0$ dependent LTP and rapidly removed from synapses by endocytosis during LTD through pathways involving PDZ scaffolds and F-actin (Carroll et al., 2001; Sheng and Lee, 2001). AMPA receptor activity and phosphorylation are also bi-directionally regulated during LTP and LTD by calcium/calmodulindependent protein kinase II (CaMKII), cAMP-dependent protein kinase (PKA), protein phosphatase $2 \mathrm{~B}$-calcineurin $(\mathrm{CaN})$, and protein phosphatase 1 (PP1) (Mulkey et al., 1994; Barria et al., 1997, Lee et al., 1998, 2000; Morishita et al., 2001). Importantly, these kinases and phosphatases also regulate receptor trafficking in plasticity; for instance, synaptic delivery of AMPA receptors during LTP requires CaM KII (Hayashi et al., 2000; Shi et al., 2001). In addition, AMPA receptor endocytosis under LTD conditions requires $\mathrm{CaN}$, and receptor recycling requires PKA (Beattie et al., 2000; Ehlers, 2000).

Mechanisms regulating PKA and $\mathrm{CaN}$ localization that are likely to be important for coordinating AMPA receptor phosphorylation and trafficking have not been studied extensively. Human A-kinase anchoring protein (AKAP) 79/rat AKAP150 (AKAP79/150) is a postsynaptic scaffold protein for PKA and $\mathrm{CaN}$ that may play an important role in these processes (Bregman et al., 1989; Carr et al., 1992; Coghlan et al., 1995). AKAP79/150 binds to PSD-95 and synapse-associated protein (SAP)97 MAGUKs in complexes with NMDA and AMPA receptors, respectively (Colledge et al., 2000). AKAP-PKA anchoring regulates AMPA-receptor activity in hippocampal neurons and GluR1 subunit phosphorylation through SAP97 in transfected cells (Rosenmund et al., 1994; Colledge et al., 2000; Tavalin et al., 
2002). Thus, here we seek to characterize AKAP79/150 targeting mechanisms that control PKA and $\mathrm{CaN}$ signaling and association with PSD-MAGUKs.

AKAP79 is targeted to plasma membranes by three N-terminal basic regions that bind acidic phospholipids, including phosphatidylinositol-4,5-bisphosphate (PI-4,5- $\mathrm{P}_{2}$ ) (Dell'Acqua et al., 1998). Each of these basic regions is similar to the effector domain of myristoylated alanine-rich C-kinase substrate (MARCKS) that binds membrane PI-4,5- $\mathrm{P}_{2}$ and F-actin (Aderem, 1992; Tall et al., 2000; Wang et al., 2001). Here we demonstrate that the AKAP79 N-terminal domain binds F-actin and targets to PI-4,5- $\mathrm{P}_{2}$ and actin-rich membrane ruffles and neuronal dendritic spines. We show that F-actin is required for postsynaptic localization of AKAP79/150 with PKA, CaN, and PSD-MAGUKs. Importantly, we demonstrate that association of the AKAP79/150-PKA complex with PSD-MAGUKs is regulated by $\mathrm{F}$-actin dynamics and NMDA receptor-CaN signaling pathways that others have implicated in AMPA receptor regulation during LTD.

\section{MATERIALS AND METHODS}

Primary culture and transfection of rat hippocampal neurons. The hippocampus was dissected from brains of Sprague Dawley neonatal rats $(0-1 \mathrm{~d})$ and dissociated by papain digestion. Neurons were plated at low density (75-100,000 cells/ml) in MEM, 10\% FBS (Invitrogen, Rockville, $\mathrm{MD})$ on poly-D-lysine, laminin-coated glass coverslips and cocultured with glia previously plated on a separate coverslip (in six-well plates) by the sandwich culture method of Goslin et al. (1998) (see Fig. 1A). After $1 \mathrm{~d}$ the media was replaced with Neurobasal supplemented with B-27 (Invitrogen) and mitotic inhibitors [uridine+fluoro-deoxyuridine (Ur+FdUr)]. The neurons were then fed with Neurobasal, B-27, Ur + FdUr by replacing half the media on day 4 and then twice weekly for the period of 1-4 weeks in culture. For the remaining experiments, neurons were plated at medium-high density $(200-300,000 \mathrm{cells} / \mathrm{ml})$ in MEM, $10 \%$ FBS on coverslips in 12-well plates. After $1 \mathrm{~d}$ the media was replaced with Neurobasal, B-27, Ur+FdUr. The neurons were then fed by replacing half the media on day 4 and then weekly with feedings on days 11 and 18. Neurons were subjected to pharmacological treatments and fixed for immunocytochemistry on days 16-20. For immunoblotting and immunoprecipitation experiments, neurons were plated at high density $(300-400,000$ cells $/ \mathrm{ml})$ on $6 \mathrm{~cm}$ Petri plates. For expression of AKAP79-green fluorescent protein (GFP) fusion proteins (vectors described below), 12-14 d in vitro (DIV) neurons cultured at medium-high density in 12-well plates were transfected by Helios Gene Gun Biolistic methods (Bio-Rad, Hercules, CA) with $\sim 1 \mu \mathrm{g}$ cDNA per well coated on $0.6-1.0 \mu \mathrm{m}$ gold particles injected at $120-160 \mathrm{psi}$. Neurons were fixed and stained for immunofluorescence microscopy (described below) $36-48 \mathrm{hr}$ after transfection.

COS7 cell culture and transfection. COS7 cells at 20-50\% confluency (24-48 hr after plating on glass coverslips in six-well plates) were transfected by calcium phosphate precipitation with the appropriate cDNA expression constructs (1-2 $\mu \mathrm{g}$ each plasmid) for $4-6 \mathrm{hr}$ at $5 \%$ $\mathrm{CO}_{2}, 37^{\circ} \mathrm{C}$. Cells were then washed twice with PBS, fed with DMEM, $10 \%$ FBS, $1 \%$ penicillin/streptomycin (Invitrogen), and grown for 24-48 $\mathrm{hr}$ before fixation and immunochemical staining as described below. Construction of pEGFPN1-AKAP79WT full-length and (1-153) basic targeting domain vectors has been described previously (Dell'Acqua et al., 1998). The AKAP79 (150-427) fragment lacking the basic targeting domains was subcloned into PstI-BamHI-digested pEGFPC2 (Clontech, Palo Alto, CA) to express a GFP-(150-427) N-terminal fusion protein in cells. The mouse PKA-RII $\alpha$ coding sequence was subcloned from pET11-RII (Hausken et al., 1996) by PCR as a HindIII-BamHI fragment into pEGFPN3 (Clontech). pECFPN1-AKAP79 and (1-153) were made by BamHI-NotI exchange of GFP with cyan fluorescent protein (CFP). pEGFPN1-phospholipase C- $\delta$ pleckstrin-homology domain (PLC $\delta$-PH) was provided by Ed Tall and Mario Rebecchi (State University of New York, Stonybrook, NY) (Tall et al., 2000); pEYFPN1-PLC $\delta$-PH was then made by BamHI-NotI exchange of GFP with yellow fluorescent protein (YFP).

Immunocytochemistry and digital fluorescence microscopy. Cultured hippocampal neurons or COS7 cells on glass coverslips were washed in PBS, fixed in $3.7 \%$ formaldehyde/PBS (10 min), and permeabilized with
$0.2 \%$ Triton $\mathrm{X}-100$ in PBS (10 min). Cells were then washed with PBS and blocked in PBS $+10 \%$ BSA for 30-60 min. The primary antibodies were incubated for $1-2 \mathrm{hr}$ at room temperature in PBS + BSA. Primary antibodies were used as follows: 1:500 rabbit anti-AKAP150, 1:1000 rabbit anti-AKAP79 (Dr. Yvonne Lai, ICOS, Bothel, WA); 1:100 mouse anti-PSD-95 (ABR, Golden, CO); 1:500 mouse anti-synapsin (Chemicon, Temulca, CA); 1:100 mouse anti-GABA $\mathrm{A}$ receptor (Chemicon); 1:200 anti-myc-9E10 (Santa Cruz Biotechnologies, Santa Cruz, CA); 1:100 rabbit anti-GluR1 (UBI, Lake Placid, NY); 1:200 mouse pan-antiPSD-MAGUK family (UBI); 1:200 mouse anti-PKA-RII $\beta$ (Transduction Labs, Los Angeles, CA); 1:500 mouse anti-CaNB (UBI). After incubation with primary antibodies the cells were washed extensively in PBS + BSA and incubated for $1 \mathrm{hr}$ with fluorescent secondary antibody conjugates [goat anti-mouse- or goat anti-rabbit-Texas Red 1:250, -FITC 1:500, or -Cy5 1:250 (Molecular Probes, Eugene, OR, or Jackson ImmunoResearch, West Grove, PA) or Texas Red-phalloidin 1:200 (Molecular Probes)]. Coverslips were then washed in PBS and water and mounted on glass slides with Pro-long (Molecular Probes). For the AKAP79-CFP/ PLC $\delta$-PH-YFP colocalization studies, COS7 cells were placed in a chamber (Molecular Probes) for live cell imaging. Specific indirect fluorescence and intrinsic GFP, CFP, or YFP fluorescence were detected with chroma filter sets using a Nikon TE-300 inverted microscope (100Xplan-apo, oil, 1.4 numerical aperture) equipped with Micromax or Sensicam digital CCD camera and Slidebook 3.0 software (Intelligent Imaging Innovations, Denver, CO). Images were exported from Slidebook as TIFF files and assembled using Adobe Photoshop 5.5.

Image quantitation was performed in Slidebook using Masks and Segmentation. Briefly, for calculation of normalized mean fluorescence intensities for immunostaining, both red-Texas Red and green-FITC channels were segmented together to generate a total neuron mask (T) including only areas of continuous pixels corresponding to the cell(s) of interest with background removed. A separate mask was drawn for the soma (S) and subtracted from the T mask to generate a dendrite (D) mask. Mean fluorescence intensities were calculated from the D and S masks for each channel and expressed as a ratio $(\% \mathrm{D} / \mathrm{S})$ as well as normalized to corresponding values for the $\mathrm{T}$ mask $(\% \mathrm{D} / \mathrm{T}$ or $\% \mathrm{~S} / \mathrm{T})$. These normalized mean intensity ratios calculated from multiple images are expressed as average percentages \pm SEM in Results or in the bar graphs in the figures. For AKAP79-GFP neuron expression studies, separate masks were drawn manually for dendritic spine heads and dendrite shafts in each image. Mean fluorescence intensities were then calculated for these masks for each image to generate a normalized ratio of spine/shaft GFP fluorescence. These normalized ratios for multiple images were then averaged and are reported \pm SEM in the text. An average spine/shaft ratio of 1 was seen for untargeted GFP; thus ratios $>1$ seen for the AKAP-GFPs reflect relative enrichment on dendritic spines.

Dendritic punctate colocalization of immunostaining was measured by generating segmented dendritic puncta masks showing discrete areas of continuous pixels of fluorescence intensity $>50 \%$ above the mean dendritic fluorescence for AKAP150 and the marker of interest (i.e., PSD$95, \mathrm{~F}$-actin, RII $\beta, \mathrm{CaN})$. Finally, a mask showing only areas of punctate dendritic colocalization for AKAP150 and the marker was generated using the "AND" function. Integrated intensity values were then calculated separately for the marker from this AKAP150 colocalization mask and the marker-specific dendritic puncta mask. The AKAP150 colocalization index for the marker was then generated by dividing the integrated intensities. These integrated colocalization indices (i.e., 150$\mathrm{RII}_{\mathrm{co}}, 150-\mathrm{CaN}_{\mathrm{co}}, \mathrm{PSD}_{\mathrm{co}}$ ) calculated from multiple images for each condition are expressed as percentages \pm SEM in Results and bar graphs in the figures. Note, this method of quantitation, although more objective than manual counting of numbers of puncta, actually underrepresents true colocalization of puncta that are overlapping but have somewhat different sizes and shapes. Nonetheless, these colocalization indices clearly give a measure of the reproducibility of the data (as shown by small SEM values) and allow meaningful comparisons between different treatment conditions. In all measurements described above, the impacts of small variations in focus and volume in images are controlled for by sampling large numbers of similar structures and the normalization provided by using ratios.

Pharmacological treatments of cultured neurons and COS7 cells. Neurons or COS7 cells plated on coverslips (for immunocytochemistry) or Petri plates (for biochemical analysis) were incubated in normal growth media for all treatments. The various treatments are described in detail in Results and in the figure legends. Reagents were obtained from the 


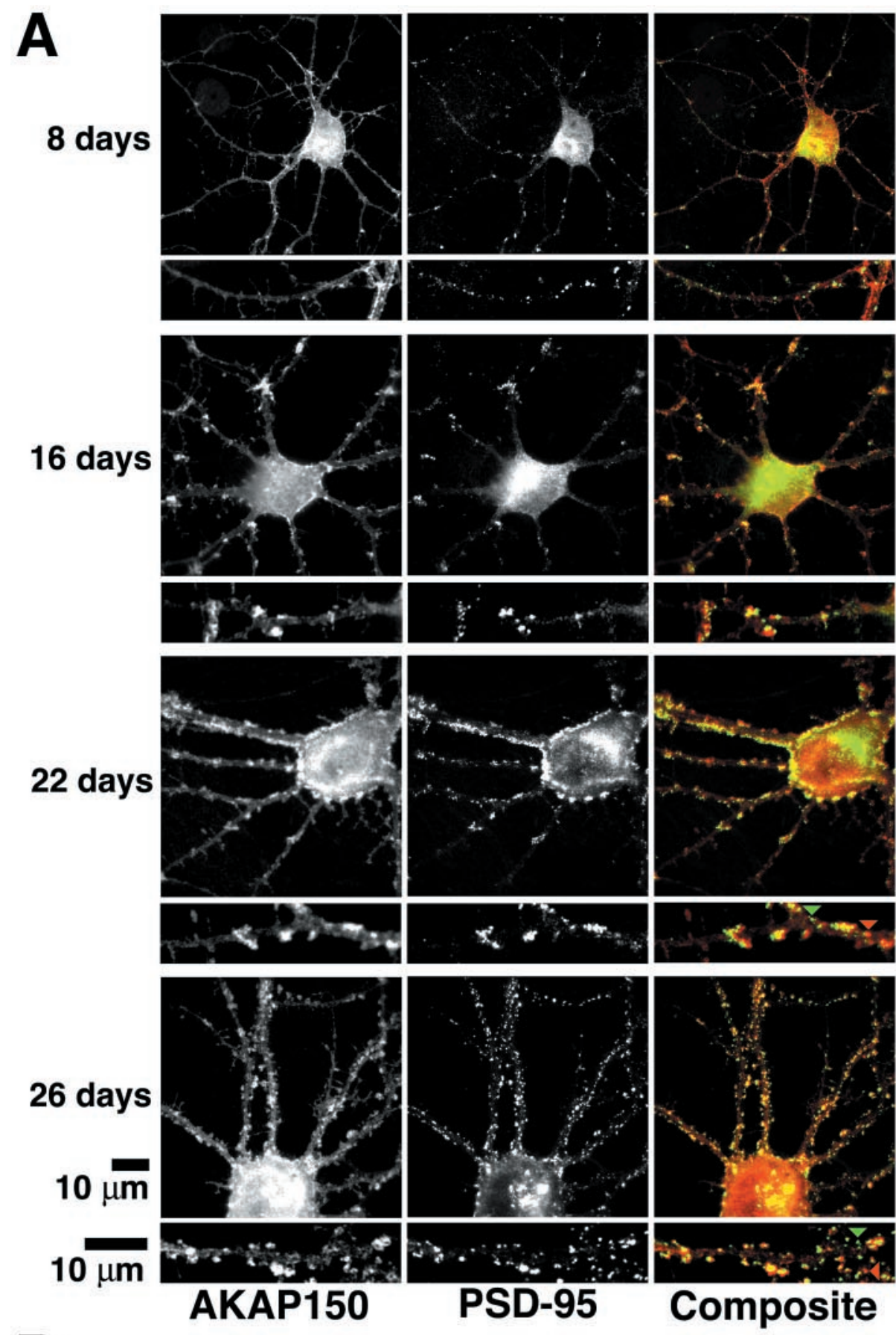

B

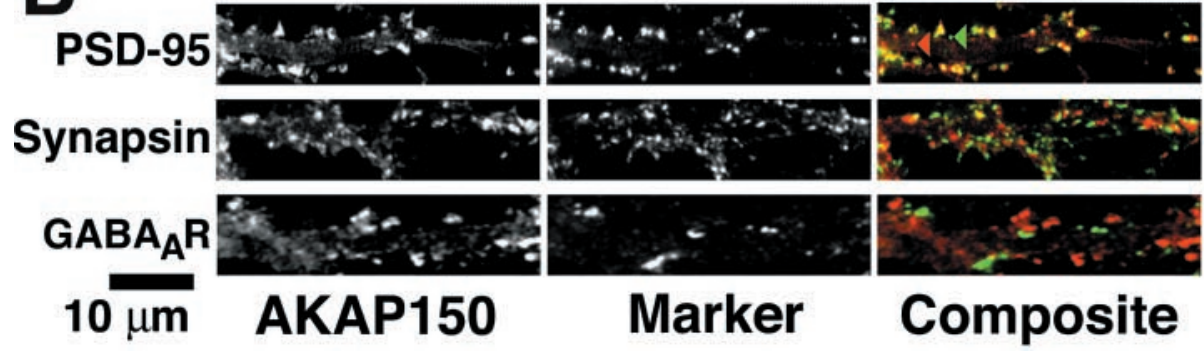

Figure 1. Postsynaptic localization of AKAP79/ 150 at excitatory synapses in hippocampal neurons. $A$, Developmental regulation of AKAP79/ 150 colocalization with the MAGUK PSD-95. Rat neonatal hippocampal neurons cultured at low density for the indicated number of days were stained for AKAP150 (red) and the postsynaptic density MAGUK PSD-95 (green). The small panels are magnifications of dendrites. $B$, Punctate colocalization of AKAP79/150 with PSD-95 on dendritic spines: proximity of AKAP79/150 puncta to presynaptic terminals stained for synapsin but not inhibitory postsynaptic elements stained for $\mathrm{GABA}_{\mathrm{A}}$ receptors. Neurons (2-3 weeks old) cultured at medium-high density were stained with anti-rat AKAP150 (red) and antiPSD-95, anti-synapsin, or anti-GABA $\mathrm{A}_{\mathrm{A}}$ receptor (all in green). Codistribution is seen as yelloworange in composite images. The red and green arrowheads point to puncta for AKAP150 and PSD-95, respectively, that are not colocalized even in "mature" dendrites. The images shown are representative of multiple neurons imaged in more than three experiments for each condition. 
following sources: L-glutamate, NMDA, AP-V, S-AMPA, and CNQX (Sigma/RBI, St. Louis, MO); latrunculin A and jasplakinolide (Molecular Probes); cytochalasin D, H-89, bis-indomaleimide I, chelerthyrine (CHE), KN-62, cyclosporin A (CsA), FK506, rapamycin, and 5,6dichloro-1- $\beta$-ribof uranosylbenzimidazole (DRB) (Calbiochem, La Jolla, CA). Electrophoresis reagents were from Bio-Rad. Other general chemicals and reagents were obtained from Sigma or Fisher Scientific (Houston, TX).

F-actin binding assay. Recombinant AKAP79WT, (1-153), and (154427) were expressed as His $_{6}$-tagged fusion proteins [AKAP79 in pET16B; (1-153) and (154-427) in pET30a] in Escherichia coli and purified by Ni-Agarose chromatography as described previously (Dell'Acqua et al., 1998). However, (1-153) was His-tagged in pET30 at the $C$ terminus in the current study, instead of the $\mathrm{N}$ terminus as in previous studies, to remove the N-terminal T7 epitope tag that contains exogenous phosphorylation sites. For actin-binding studies, N-His-AKAP79WT, N-His(154-427), or (1-153)C-His was incubated with F-actin and then assayed for binding by cosedimentation. Briefly, F-actin was polymerized from purified G-actin $(10 \mu \mathrm{M}$; Sigma) in vitro for $30 \mathrm{~min}$ in $125 \mathrm{~mm} \mathrm{KCl}, 2.5 \mathrm{~mm} \mathrm{MgCl}, 0.2 \mathrm{~mm}$ ATP, $2 \mathrm{~mm}$ Tris, pH 7.6 (F-Buffer). Actin $(2 \mathrm{mg} / \mathrm{ml})$ was stored at $4^{\circ} \mathrm{C}$ in the control G-buffer (0.2 mM ATP, $0.2 \mathrm{~mm} \mathrm{MgCl}_{2}, 2 \mathrm{~mm}$ Tris, pH 7.6). F-actin filaments or unpolymerized $\mathrm{G}$-actin was then incubated for 10 min with AKAP79WT (700 ng), (1-153) (250 ng), or (154-427) (500 ng) followed by centrifugation $(20 \mathrm{~min}, 100,000 \times g)$. The distributions of the AKAP fragments between the supernatant containing G-actin (unbound fraction) and pellet containing F-actin (bound fraction) were determined by immunoblotting with rabbit anti-AKAP79 918I, 1:2000 (ICOS), and these immunoblots are shown in Figures $3 B$ and $5 A, B, D$.

Regulation of (1-153) F-actin binding by PKC phosphorylation and CaM binding. For actin binding regulation studies, (1-153)C-His was unphosphorylated or PKC phosphorylated with unlabeled ATP as described below or incubated $10 \mathrm{~min}$ with $1 \mu \mathrm{M} \mathrm{CaM}$ (Calbiochem) with $(+)$ or without $(-) \mathrm{Ca}^{2+}(0.1 \mathrm{~mm})$ or EGTA $(5 \mathrm{~mm})$, incubated with F-actin, and then assayed for actin binding by cosedimentation. For PKC phosphorylation order experiments, (1-153)C-His was either phosphorylated with PKC for 15 min as described above and then incubated with F-actin for $10 \mathrm{~min}$ or incubated with $\mathrm{F}$-actin for $10 \mathrm{~min}$ before the addition of an equivalent amount of PKC for $15 \mathrm{~min}$ before centrifugation (note: F-buffer already contains $0.2 \mathrm{mM}$ ATP). For CaM-binding order experiments, (1-153)C-His was either incubated with $1 \mu \mathrm{M}$ CaM, $0.1 \mathrm{~mm}$ $\mathrm{Ca}^{2+}$ for 10 min before incubation with $\mathrm{F}$-actin for $10 \mathrm{~min}$ or incubated with F-actin for $10 \mathrm{~min}$ before the addition of $1 \mu \mathrm{M} \mathrm{CaM}, 0.1 \mathrm{mM} \mathrm{Ca}^{2+}$ for $10 \mathrm{~min}$ before centrifugation.

In vitro phosphorylation of the (1-153) targeting domain. Recombinant $(1-153) \mathrm{C}$-His $(1 \mu \mathrm{g})$ was PKC phosphorylated essentially as described previously (Dell'Acqua et al., 1998) except for use of a PKC constitutively active catalytic trypsin fragment (PKC-M, $20 \mathrm{ng}$ ) (provided by Dr. Michael Browning, University of Colorado Health Science Center). For direct visualization of PKC phosphorylation of (1-153)C-His, $600 \mathrm{cpm} /$ pmol $\left[\gamma-{ }^{32} \mathrm{P}\right]$ ATP was included, and the reaction was then analyzed by SDS-PAGE and imaged using a Molecular Dynamics Storm Phosphorimager. To look at competition between $\mathrm{Ca}^{2+}-\mathrm{CaM}$ binding and PKC phosphorylation, phosphorylation of (1-153) by PKC was done with or without $0.1 \mathrm{mM} \mathrm{Ca}^{2+}, 5 \mathrm{~mm}$ EGTA, and $1 \mu \mathrm{M}$ CaM as indicated.

Immunoprecipitation of AKAP79/150 complexes from hippocampal neuron cell extracts. Hippocampal neurons cultured at high density were left untreated, treated with $5 \mu \mathrm{M}$ latrunculin A for $4 \mathrm{hr}$, or treated with $50 \mu \mathrm{M}$ NMDA for $10 \mathrm{~min}$ followed by washing twice in PBS. The cells from two to five $(6 \mathrm{~cm})$ dishes each for untreated control or treated conditions were pooled and lysed in $1-2 \mathrm{ml}$ of $4{ }^{\circ} \mathrm{C}$ Triton lysis buffer (TLB) (0.5\% Triton X-100, $20 \mathrm{~mm}$ HEPES, pH 7.4, $0.1 \mathrm{~m} \mathrm{KCl,} 30 \mathrm{~mm}$ NaPPi, $50 \mathrm{~mm} \mathrm{NaF}, 1 \mathrm{~mm}$ EDTA, 1 mM EGTA, $2 \mu \mathrm{g} / \mathrm{ml}$ leupeptin/ pepstatin, $1 \mathrm{~mm}$ benzamidine, $1 \mathrm{~mm}$ 4-(2-aminoethyl)benzenesulfonylfluoride) followed by dounce homogenization to prepare whole-cell extracts. One hundred microliters of these whole-cell extracts for both untreated control and treated conditions were set aside. The remaining volumes of these extracts were clarified by centrif ugation $(20,000 \times g, 15$ $\min , 4^{\circ} \mathrm{C}$ ). The resulting supernatants were divided into two to four separate tubes with equal protein contents, and then each tube was incubated at $4^{\circ} \mathrm{C}$ overnight with $5 \mu \mathrm{g}$ of rabbit anti-AKAP 150 antibodies (ICOS). This incubation was followed by $1-2 \mathrm{hr}$ incubation with protein A-Sepharose $(25 \mu 1,50 \%$ slurry equilibrated in TLB; UBI). The immune complexes were then pelleted by microcentrif ugation $(3000 \times \mathrm{g}, 1 \mathrm{~min})$, and the beads were washed in TLB $6 \times 1 \mathrm{ml}$. The immune complexes were finally eluted with SDS-sample buffer, separated by SDS-PAGE along with cell extracts $(12.5-25 \mu \mathrm{g})$, and analyzed by immunoblotting with rabbit anti-AKAP150 (1:2000), mouse pan-anti-PSD-MAGUK family (1:1000, UBI), or mouse anti-PKA-RII $\beta$ (1:2000; Transduction Labs).

\section{RESULTS}

Previous studies have demonstrated that AKAP79/150 is the major AKAP in the PSD (Carr et al., 1992), coimmunoprecipitates with PSD-MAGUKs, and binds directly to both SAP97 and PSD-95 MAGUKs in vitro (Colledge et al., 2000). Association of AKAP79 with MAGUKs in vitro involves direct binding between an unmapped central AKAP domain and the MAGUK SH3 and GK domains (Colledge et al., 2000). However, proper membrane localization of these scaffolds clearly involves additional targeting determinants such as palmitoylation sites in PSD-95 and $\mathrm{N}$-terminal basic regions in AKAP79 (Lue et al., 1994, 1996; Li et al., 1996; Dell'Acqua et al., 1998; Wu et al., 1998; Craven and Bredt, 2000; El-Husseini et al., 2000a). Consistent with these independent targeting mechanisms, although AKAP79/150 shows extensive punctate colocalization with PSD-95 on dendritic spines in hippocampal neurons, it is also more widely distributed along dendrite spine and shaft membranes (Fig. 1). Thus, the ability of AKAP79/150 to form scaffolding complexes with PSDMAGUKs at synapses in vivo is likely to depend first on the primary mechanisms that independently target the AKAP to plasma membranes and dendritic spines. We have previously identified three $\mathrm{N}$-terminal basic regions that bind to PI-4,5- $\mathrm{P}_{2}$ and are necessary and sufficient for targeting GFP to the plasma membrane in human embryonic kidney (HEK)-293 cells and cortical neurons (Dell'Acqua et al., 1998). Each of these basic regions is similar to the basic effector domain of MARCKS that binds both membrane PI-4,5- $\mathrm{P}_{2}$ and cortical F-actin (Aderem, 1992; Bubb et al., 1999; Wang et al., 2001); however, it is not known whether the AKAP79 targeting domain also binds F-actin. Although F-actin is not necessary for AKAP79 general membrane targeting in HEK-293 cells, it is quite possible that interactions with F-actin could further direct membranelocalized AKAP to more specific structures such as dendritic spines (Li et al., 1996; Dell'Acqua et al., 1998). To evaluate this possibility, we conducted a developmental analysis of AKAP79/ 150 localization in low-density hippocampal neuron cultures across time periods when synapses first form and then mature into spiny actin-rich synapses.

\section{Postsynaptic localization of AKAP79/150 on dendritic spines in hippocampal neurons}

In neurons cultured for 8 DIV, AKAP79/150 showed nonuniform membrane localization in the soma and dendrites, including fine filopodial structures (Fig. $1 A$ ). However, at 8 DIV there was very little codistribution of AKAP79/150, with puncta for PSD-95 located primarily on dendritic shafts. By 16 DIV there was much more extensive colocalization of AKAP79/150 and PSD-95 puncta (Fig. 1A). This somatodendritic colocalization of AKAP79/150 and PSD-95 developed more during the third week in culture, and by 22-26 DIV most PSD-95 puncta overlapped with AKAP79/150 puncta, especially on dendritic spines (Fig. $1 A)$. However, even at 22-26 DIV there were still sites of AKAP79/150 staining that did not stain positive for PSD-95 and vice versa (Fig. $1 A$; see arrowheads on magnification composite panels). Similar results were obtained in medium-high-density neuron cultures that form more numerous synapses and mature more rapidly than low-density cultures. Neurons cultured at mediumhigh density for 2-3 weeks showed extensive but still not complete 
A

Composite AKAP150

F-Actin

PSD-95

$10 \mu \mathrm{m}$

C

$+\operatorname{Ltr} A$
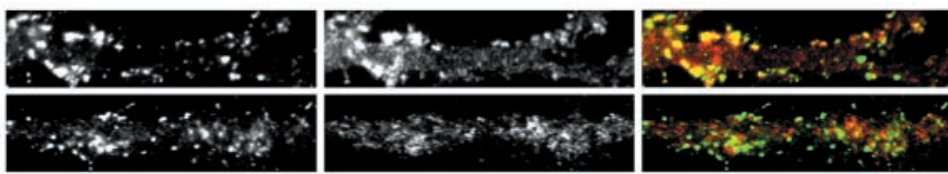

$10 \mu \mathrm{m}$

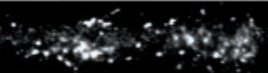

PSD-95

Control

Untreated
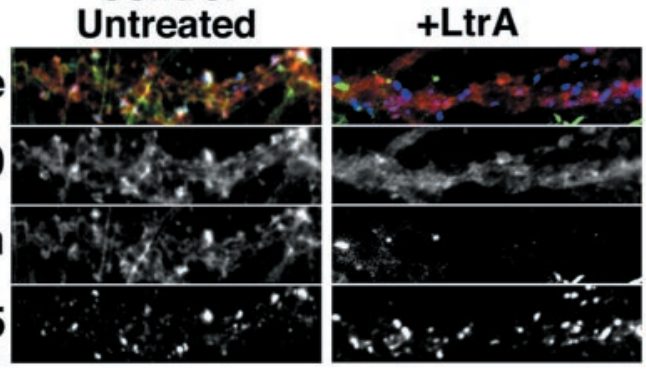

+LtrA, wash

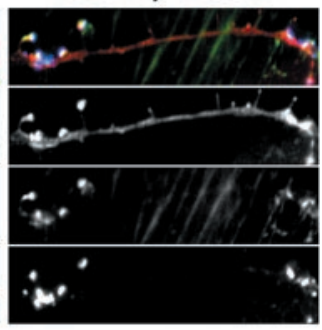

$10 \mu \mathrm{m}$

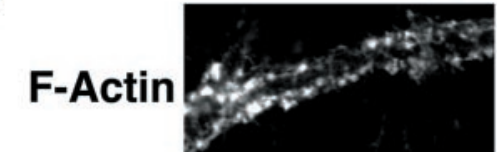

Control Untreated
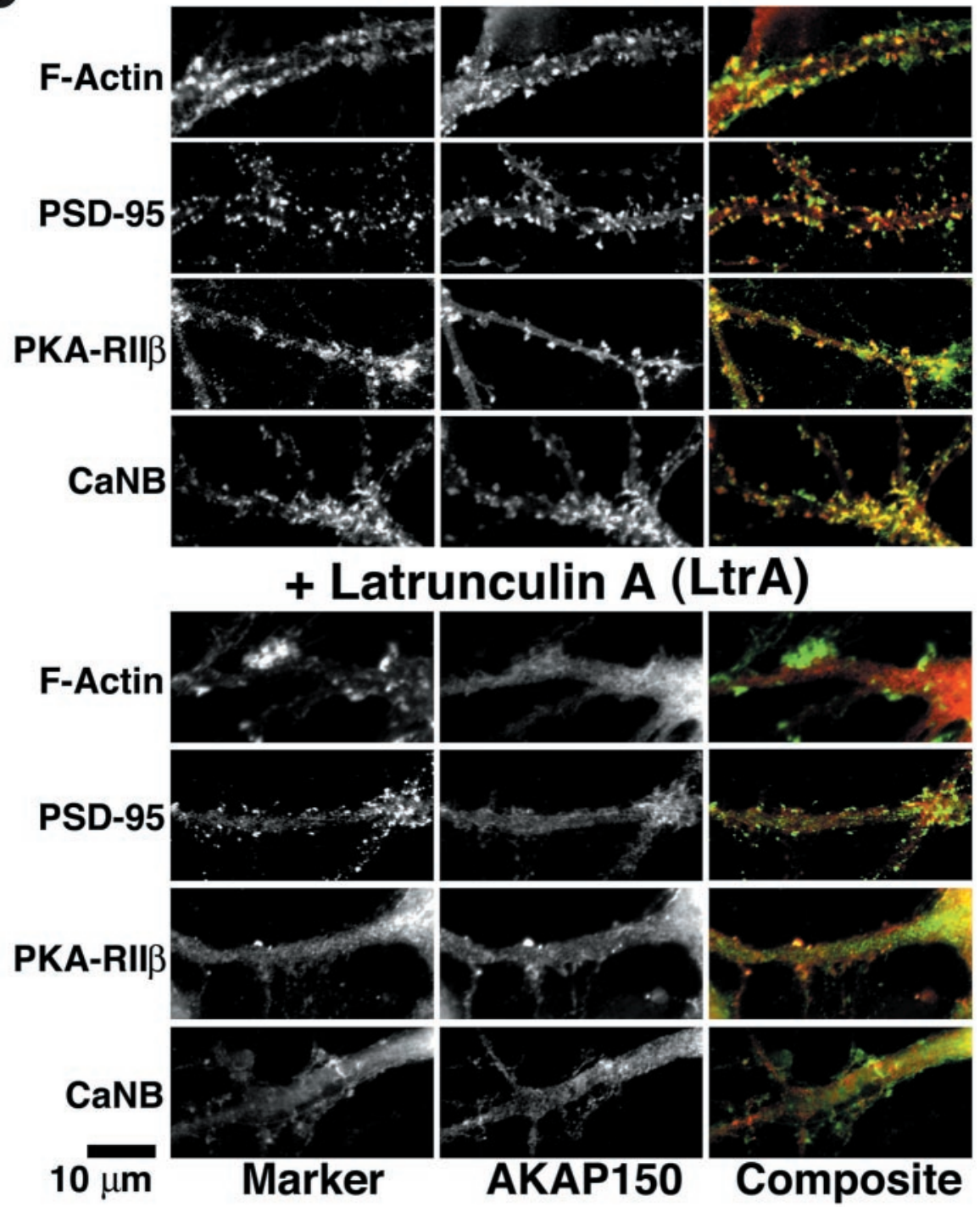

AKAP150
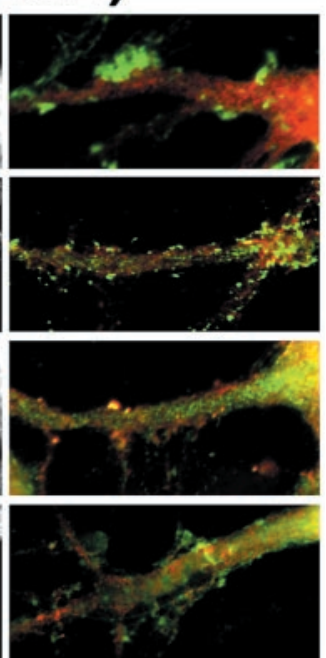

Composite
Figure 2. AKAP79/150 colocalization with F-actin, PSD-95, PKA, and calcineurin on dendritic spines depends on the actin cytoskeleton: disruption with latrunculin A. $A$, AMPA receptor GluR1 (red) dendritic colocalization with PSD-95 (green) is disrupted by pretreatment with latrunculin A (+LtrA; $5 \mu \mathrm{M}, 2 \mathrm{hr})$. B, Dendritic spine colocalization in hippocampal neurons (seen as white in Composite panels) of AKAP79/150 (red) with F-actin (green) and PSD-95 (blue) is disrupted by latrunculin A treatment $(2 \mu \mathrm{M} ; 2 \mathrm{hr})$ and is reversible after drug washout and recovery (16 hr). C, Dendritic spine colocalization of AKAP79/150 (red) with CaN and PKA as well as PSD-95 and F-actin (markers; all in green) is disrupted by latrunculin A $(5 \mu \mathrm{M}, 2 \mathrm{hr})$. Magnifications of dendrites are shown. See Results for quantitation. 


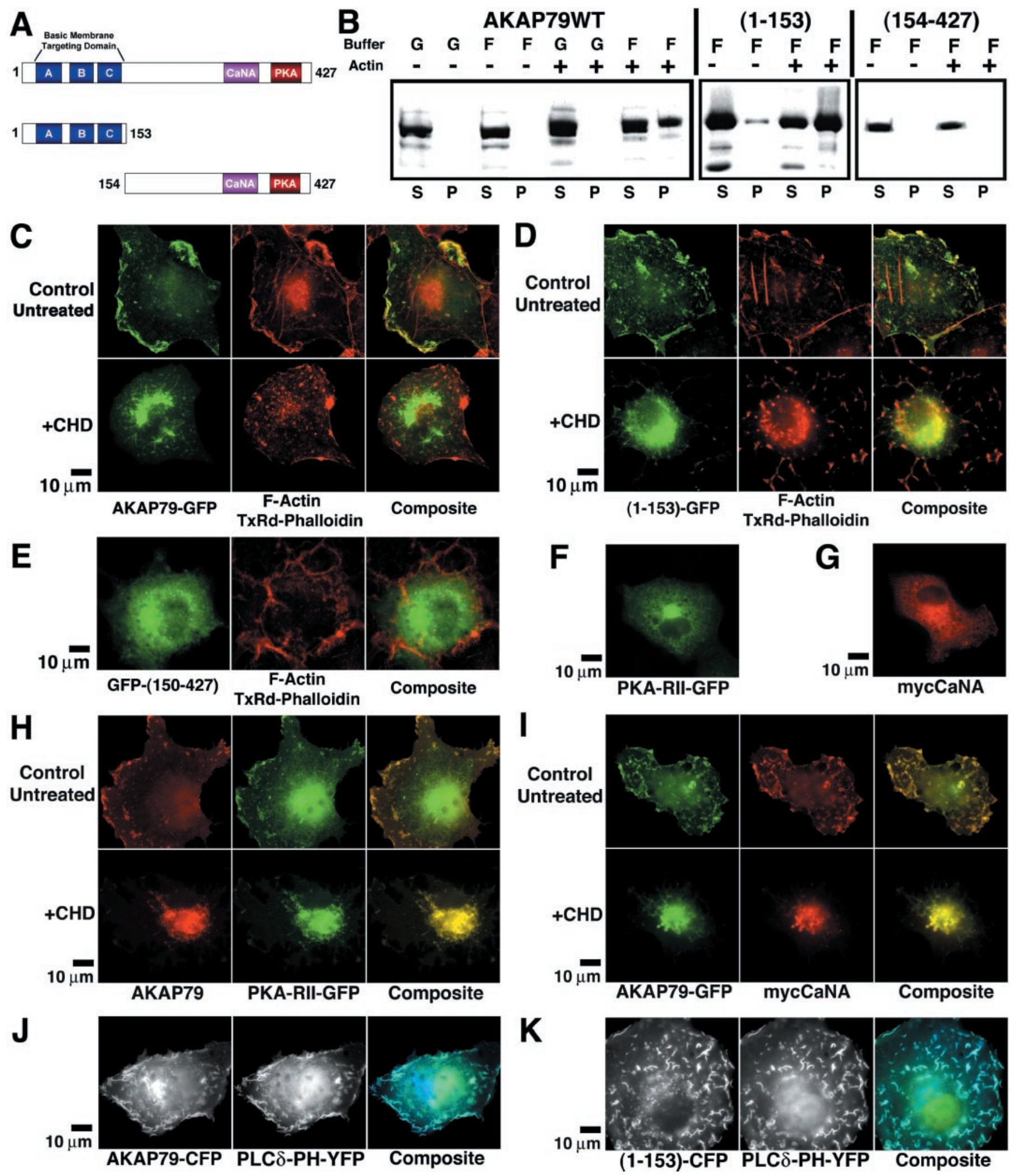

Figure 3. The AKAP79 N-terminal basic domain binds F-actin in vitro and localizes with PI-4,5-P ${ }_{2}$ and cortical F-Actin in COS7 cells: targeting of PKA and CaN to membrane ruffles. $A$, Diagram showing the structures of AKAP79WT(1-427), (1-153), and (154-427) proteins used for actin-binding studies. Locations of the three $(A, B, C)$ basic membrane targeting/phospholipid binding regions and the CaNA and PKA-RII anchoring domains are indicated. $B$, AKAP79WT and an N-terminal (1-153) fragment but not a C-terminal (154-427) fragment bind to F-actin in vitro. Purified full-length AKAP79WT, (1-153), or (154-427) fragments were incubated with $(+)$ or without $(-)$ purified actin in buffers favoring monomeric G-actin $(G)$ or F-actin polymerization $(F)$. Binding to polymerized F-actin was detected as sedimentation of AKAP79 immunoreactivity in pellet fractions $(P)$ after centrifugation. The data shown are representative of results obtained in multiple (more than three) independent experiments. $C$, AKAP79-GFP colocalizes with cortical/membrane F-actin in COS7 cells. In control untreated COS7 cells, overlap of AKAP79-GFP (green) (Figure legend continues.) 
dendritic colocalization of AKAP79/150 with PSD-95 (Fig. 1B, arrowheads). Costaining of neurons for AKAP79/150 and synapsin reveals that most of the AKAP79/150 puncta seen in these dendrites are closely opposed to presynaptic terminals (Fig. 1B). Specificity in this localization of AKAP79/150 to excitatory over inhibitory synapses was seen in very little overlap between den-

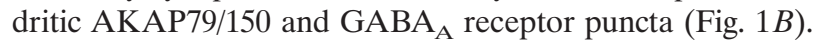

\section{Postsynaptic localization of AKAP79/150 depends on the dendritic actin cytoskeleton}

This developmental progression of AKAP79/150 colocalization with PSD-95 closely parallels time courses elucidated by others for the formation of F-actin-rich dendritic spines and recruitment of glutamate receptors and PSD-95 to spiny synapses (Rao et al., 1998; Pickard et al., 2000; Okabe et al., 2001; Zhang and Benson, 2001). Importantly, postsynaptic localization of AMPA receptors depends on F-actin and is disrupted by the actin polymerization inhibitor latrunculin A (Allison et al., 1998, 2000; Shen et al., 2000; Zhou et al., 2001). In agreement with previous studies on AMPA receptors and as a positive control, treatment with latrunculin A caused decreased dendritic colocalization of GluR1AMPA receptors with PSD-95 (Fig. 2A). Consistent with possible targeting of AKAP79/150 to postsynaptic actin, in untreated neurons AKAP79/150 exhibited colocalization with phalloidinstained F-actin and PSD-95 on dendritic spines (Fig. 2B,C). After latrunculin treatment, AKAP79/150 assumed a more diffuse pattern in dendrites, with very little F-actin colocalization (Figs. $2 B, C)$. Importantly, treatment with latrunculin also disrupted AKAP79/150 codistribution with PSD-95 (Figs. 2B,C), which remained punctate, as seen in previous studies (Allison et al., 1998, 2000). These effects of latrunculin on AKAP79/150 colocalization with F-actin and PSD-95 on dendritic spines were reversible after removal of the drug and a recovery period to allow repolymerization of spine actin (Fig. $2 B$ ). These findings indicate that, like AMPA receptors, the dendritic F-actin cytoskeleton is important for maintaining postsynaptic localization of AKAP79/150.

Quantitation of neurons from multiple experiments $(n=3-5)$ revealed AKAP150-integrated colocalization indices (see Materials and Methods) of $65 \pm 9 \%$ for F-actin and $66 \pm 3 \%$ for PSD-95 $\left(\mathrm{PSD}_{\mathrm{co}}\right)$ in untreated neurons. After latrunculin treatment, these indices fell to $22 \pm 6$ and $19 \pm 6 \%$ for F-actin and $\mathrm{PSD}_{\mathrm{co}}$, respectively. This loss of AKAP79/150 from the PSD might be expected to result in a corresponding change in localization of PKA and $\mathrm{CaN}$ anchored to it. In control neurons, both PKA-RII $\beta$ and CaNB staining showed extensive punctate codistribution with AKAP79/150 on dendritic spines with colocalization indices of $150-\mathrm{RII}_{\mathrm{co}}=73 \pm 4 \%$ and $150-\mathrm{CaN}_{\mathrm{co}}=68 \pm 3 \%$, respectively (Fig. 2D) $(n=3-5)$. However, after treatment of neurons with latrunculin, punctate codistribution of PKA and
CaN with AKAP79/150 was lost, with all three proteins exhibiting primarily diffuse dendritic localization (Fig. 2D). Without numerous AKAP150, PKA-RII $\beta$, or CaNB puncta to quantitate after latrunculin treatment, accurate colocalization indices could not be calculated. However, calculation of normalized mean fluorescence values (see Materials and Methods; $\mathrm{D} / \mathrm{T}$ ratio) revealed corresponding $17-21 \%$ decreases in overall dendritic localization caused by latrunculin treatment for AKAP150 [81 \pm $3 \%$ Control; $63 \pm 3 \%$ latrunculin A (LtrA)], PKA-RII $\beta$ (70 \pm $3 \%$ Control; $53 \pm 2 \% \mathrm{LtrA})$, and CaNB (76 $\pm 4 \%$ Control; $55 \pm 3 \%$ LtrA), suggesting that a significant amount of PKA and $\mathrm{CaN}$ might be moving as a unit with the AKAP. Thus, the actin cytoskeleton is necessary for maintaining proper dendritic localization of multiple components of the AKAP79/150 scaffold.

\section{The AKAP79 N-terminal basic domain binds F-actin and mediates targeting to the cortical membrane cytoskeleton in COS7 cells}

In light of the results of these latrunculin studies and the similarities of the AKAP N-terminal basic domains with the MARCKS effector domain, we assayed purified recombinant AKAP79WT, an N-terminal targeting domain (1-153) fragment, and a C-terminal (154-427) control fragment (Fig. 3A) for direct binding to F-actin using cosedimentation methods. We observed direct binding of AKAP79 to F-actin as seen in cosedimentation of AKAP79 in the F- but not G-actin pellet fractions (Fig. 3B). An additional control for nonspecific aggregation is that AKAP79 did not sediment in the absence of actin in either G- or F-buffer conditions. Importantly, a recombinant N-terminal (1-153) fragment corresponding to the previously mapped basic membrane targeting and $\mathrm{PI}-4,5-\mathrm{P}_{2}$ binding domain also exhibited specific cosedimentation with F-actin (Fig. $3 B$ ). In contrast, a C-terminal (154-427) control fragment lacking the basic domains but containing the $\mathrm{CaN}$ and PKA anchoring domains (Fig. $3 A$ ) did not cosediment with F-actin (Fig. 3B).

We next sought to determine whether this N-terminal basic domain that binds F-actin in vitro might also be sufficient for targeting to the membrane actin cytoskeleton in a model cell system. We transfected COS7 cells with full-length AKAP79 tagged with GFP (Tsien, 1998) and then costained for F-actin with phalloidin (Fig. 3C). In control cells, AKAP79-GFP exhibited plasma membrane localization characterized by prominent enrichment with F-actin in membrane ruffles but not cytoplasmic stress fibers (Fig. 3C). After disruption of F-actin with the polymerization inhibitor cytochalasin D, AKAP79-GFP colocalization with F-actin was eliminated, and the AKAP assumed a diffuse plasma membrane localization with significant accumulation in intracellular membrane structures and aggregates (Fig. $3 C$ ). Importantly, an N-terminal (1-153)-GFP protein also displayed specific localization to F-actin ruffles, and this localization

\section{$\leftarrow$}

(Figure legend continued.) and F-actin (TxRd-Phalloidin; red) in plasma membrane ruffles is seen as yellow-orange in the composite image. Treatment of AKAP79-GFP-transfected COS7 cells with the actin polymerization inhibitor cytochalasin D (5 $\mu \mathrm{M}, 4-5 \mathrm{hr})(+\mathrm{CHD})$ disrupts both the actin cytoskeleton and AKAP79-GFP/F-actin colocalization in membrane ruffles. $D$, The AKAP79(1-153)-GFP (green) N-terminal targeting domain also colocalizes with cortical F-actin (red) ruffles in a cytochalasin D (+CHD)-sensitive manner. E, The GFP-AKAP79(150-427) (green) C-terminal fragment containing CaNA and PKA anchoring domains but lacking the basic targeting domains is localized to the cytoplasm and not colocalized with cortical F-actin (red) in COS7 cells. PKA-RII-GFP $(F$, green) and mycCaNA (anti-myc; $G$, red) are found in the cytoplasm when expressed alone in COS7 cells. $H$, Coexpression of AKAP79 (anti-79, red) targets PKA-RII-GFP ( green) to plasma membrane ruffles in a cytochalasin D (+CHD)sensitive manner. I, Coexpression of AKAP79-GFP (green) targets mycCaNA (anti-myc; red) to plasma membrane ruffles in a cytochalasin D $(+C H D)$-sensitive manner. $J$, Colocalization (blue-green) of AKAP79-CFP (blue) with PI-4,5- $\mathrm{P}_{2}$ detected by PLC $\delta$-PH-YFP (green) in membrane ruffles of living COS7 cells. K, Colocalization (blue-green) of the AKAP79(1-153)-CFP N-terminal targeting domain (blue) with PI-4,5-P 2 detected by PLC $\delta$-PH-YFP ( green) in membrane ruffles of living COS7 cells. The images shown in $C-K$ are representative of multiple cells imaged in three independent experiments for each condition. TxRd, Texas Red. 




Figure 4. The AKAP79 N-terminal basic domain targets to dendritic spines in hippocampal neurons. A, Targeting of AKAP79-GFP and the N-terminal basic domain (1-153)-GFP but not GFP alone (all in green) to dendritic spines in transfected neurons. $B$, Colocalization of AKAP79-GFP and (1153)-GFP (both green) with F-actin and PSD-95 (both red) on dendritic spines. See Results and Materials and Methods for quantitation and details.
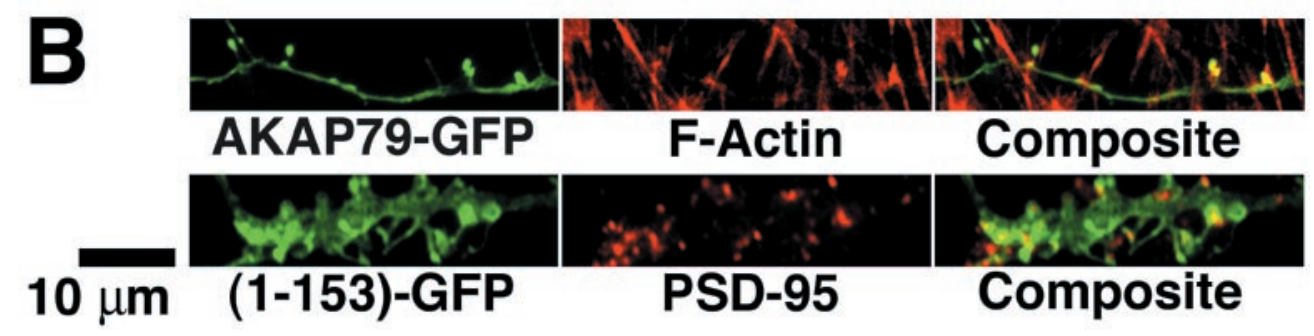

was sensitive to disruption with cytochalasin $\mathrm{D}$ (Fig. $3 D$ ). In contrast, a GFP-(150-427) control fusion protein lacking the $\mathrm{N}$-terminal basic domains was cytoplasmic and showed no localization with membranes or cortical actin in COS7 cells (Fig. $3 E$ ). Thus, the N-terminal basic regions of AKAP79 appear to be necessary and sufficient for targeting to cortical/membrane actin structures in cells.

Our findings above suggest that inhibition of F-actin polymerization in neurons may disrupt dendritic spine localization of PKA and CaN through mislocalization of AKAP79/150. In support of this model, PKA-RII-GFP and mycCaNA subunits are cytoplasmic when expressed alone in COS7 cells (Figs. $3 F, G$ ) but are targeted to the membrane and enriched in ruffles when coexpressed with AKAP79 (Fig. 3H,I). Importantly, disruption of F-actin with cytochalasin D caused loss of membrane ruffle localization of PKA or CaN with AKAP79, diffuse plasma membrane localization, and the appearance of these proteins in intracellular structures (Figs. 3H,I). Thus, disrupting postsynaptic targeting of AKAP79/150, the predominant AKAP in the PSD, is likely to also alter dendritic spine localization of PKA and $\mathrm{CaN}$ in neurons as seen in Figure 2. In addition, from the results of all of these COS7 studies, it seems reasonable that the diff use dendritic localizations seen for AKAP79/150, PKA, and CaN in latrunculin-treated neurons is the product of both lateral membrane diffusion away from synapses as well as some redistribution to intracellular membranes.

Our previous studies showed that the AKAP79 basic targeting domains, like the MARCKS effector domain, could bind through nonspecific electrostatic interactions to membranes containing acidic phospholipids such as PI-4,5- $\mathrm{P}_{2}$. Interestingly, cellular imaging studies using PLC $\delta$-PH, which binds with high affinity and specificity to PI-4,5- $\mathrm{P}_{2}$, have shown enrichment of PI-4,5- $\mathrm{P}_{2}$ with actin in plasma membrane ruffles (Tall et al., 2000). Thus, we wanted to examine whether the AKAP79 N-terminal basic domain might also colocalize with PI-4,5- $\mathrm{P}_{2}$ in membrane ruffles. To make this inquiry possible, we generated AKAP79 full length and (1-153) tagged with cyan-CFP and the PLC $\delta$-PH domain tagged with yellow-YFP for simultaneous imaging in live cells. Coexpression of either AKAP79-CFP (Fig. 3J) or (1-153)-CFP (Fig. $3 K$ ) with PLC $\delta$-PH-YFP revealed extensive codistribution of CFP and YFP fluorescence in membrane ruffles of living COS7 cells. Some intracellular vesicular membrane localization of AKAP79 and (1-153)-CFP that was independent of PHPLC $\delta$-YFP was also seen (Fig. $3 J, K$ ). However, the extensive overlap of AKAP79(1-153) with PLC $\delta$-PH in ruffles clearly shows significant enrichment of the AKAP targeting domain and PI-4,5-P $\mathrm{P}_{2}$ in the same plasma membrane structures. These findings suggest that multiple electrostatic interactions of the three AKAP79 N-terminal basic regions, like the MARCKS basic domain, may allow the AKAP to link plasma membrane PI-4,5- $\mathrm{P}_{2}$ to cortical actin in ruffles.

\section{The AKAP79 N-terminal basic domain mediates targeting to dendritic spines in hippocampal neurons}

We next wanted to establish that this same $\mathrm{N}$-terminal basic region that targeted to cortical actin and PI-4,5- $\mathrm{P}_{2}$ membrane structures in COS7 cells was also involved in targeting AKAP79 to dendritic spines in neurons. Previously, we demonstrated that this region could target to somatodendritic plasma membranes in microinjected cortical neurons; however, specific colocalization with F-actin or PSD-MAGUKs at synapses was not addressed (Dell'Acqua et al., 1998). Expression of either full-length AKAP79-GFP or (1-153)-GFP containing just the N-terminal basic domain resulted in targeting of GFP to plasma membrane sites in both the soma and dendrites of transfected neurons (Fig. $4 A$ ). In contrast, GFP alone was clearly cytoplasmic and diff usely distributed throughout the soma and dendrites (Fig. 4A). Dendritic localization of both AKAP79 and (1-153) was characterized by punctate enrichment on dendritic spines (Fig. $4 A$ ), where colocalization with F-actin or PSD-95 could be seen (Fig. $4 B$ ). Enrichment on dendritic spines was quantitated by $30-50 \%$ higher average spine/shaft normalized mean fluorescence ratios for AKAP79 $(1.55 \pm 0.1 ; n=10)$ and $(1-153)-\operatorname{GFP}(1.33 \pm 0.03$; $n=13)$ relative to GFP alone $(1.05 \pm 0.06 ; n=11)$, which showed 
A

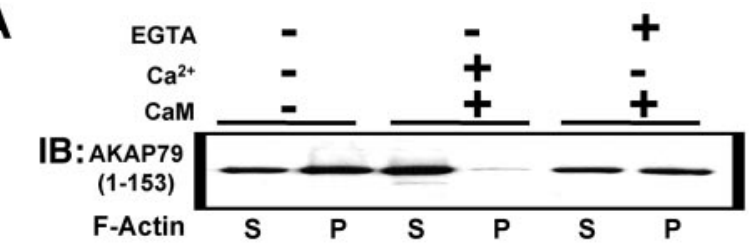

B

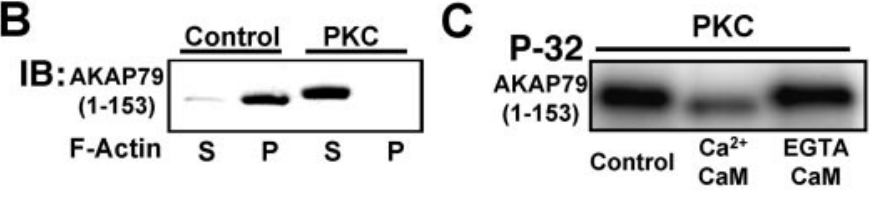

D

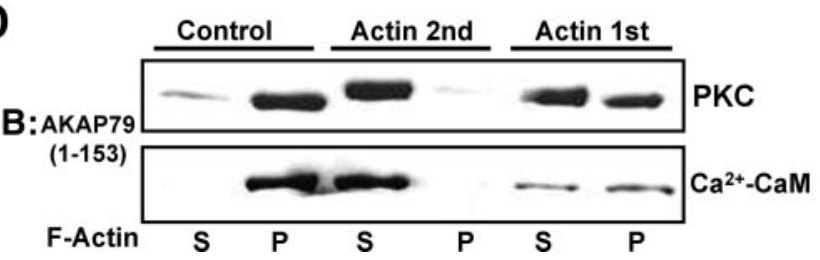

Figure 5. Regulation of AKAP79 targeting domain F-actin binding by phosphorylation and $\mathrm{Ca}^{2+}$-calmodulin binding. $A$, Regulation of AKAP79(1-153) F-actin binding by $\mathrm{Ca}^{2+}-\mathrm{CaM}$. AKAP79(1-153) was incubated for $10 \mathrm{~min}$ as indicated with $(+)$ or without $(-)$ CaM $(1 \mu \mathrm{M})$, $\mathrm{Ca}^{2+}(100 \mu \mathrm{M})$, or EGTA $(5 \mathrm{mM})$ before assaying for F-actin binding by cosedimentation. $B$, Regulation of AKAP79(1-153) F-actin binding by PKC phosphorylation. AKAP79(1-153) was PKC phosphorylated before assaying for $\mathrm{F}$-actin binding by cosedimentation. Control incubations were incubated in the absence of kinase. $C$, Competition between $\mathrm{Ca}^{2+}$ $\mathrm{CaM}$ binding and PKC phosphorylation of the AKAP79(1-153) targeting domain. AKAP79(1-153) was phosphorylated with $\left[\gamma-{ }^{32} \mathrm{P}\right] \mathrm{ATP}$ by PKC (Control), with $\mathrm{Ca}^{2+}-\mathrm{CaM}$ or $\mathrm{CaM}$ and EGTA present. D, Previous incubation with F-actin inhibits regulation of AKAP79(1-153) F-actin binding by $\mathrm{PKC}$ phosphorylation and $\mathrm{Ca}^{2+}-\mathrm{CaM}$ binding. In the top panel, AKAP79(1-153) was either phosphorylated by PKC before incubation with F-actin (Actin 2nd; as in B) or incubated first with F-actin and then with PKC (Actin 1st) followed by assaying for F-actin cosedimentation. In the bottom panel, the AKAP79(1-153) targeting domain fragment either was incubated with $\mathrm{Ca}^{2+}-\mathrm{CaM}$ before incubation with $\mathrm{F}$-actin (Actin 2nd; as in $A$ ) or was incubated first with F-actin and then with $\mathrm{Ca}^{2+}-\mathrm{CaM}$ (Actin 1st) followed by assaying for $\mathrm{F}$-actin cosedimentation. The data shown are representative of results obtained in at least three independent experiments. $A, B$, and $D$ are immunoblots $(I B:) ; C$ is an autoradiogram $(P-32)$.

equal distribution between dendritic spines and shafts. These findings suggest that the $\mathrm{N}$-terminal basic domain is sufficient for targeting AKAP79 to dendritic spines in hippocampal neurons.

\section{Regulation of AKAP79 targeting domain binding to F-actin by phosphorylation and calmodulin binding}

The three basic regions of the AKAP79 targeting domain contain serine/threonine phosphorylation sites and bind $\mathrm{Ca}^{2+}-\mathrm{CaM}$ (Faux and Scott, 1997; Dell'Acqua et al., 1998). We have shown previously that in vitro binding of the AKAP79(1-153) targeting domain to $\mathrm{PI}-4,5-\mathrm{P}_{2}$ is regulated by $\mathrm{PKC}$ phosphorylation and $\mathrm{Ca}^{2+}-\mathrm{CaM}$ binding (Dell'Acqua et al., 1998). Thus, it is likely that binding of the AKAP79 targeting domain to F-actin is also regulated by $\mathrm{PKC}$ and $\mathrm{CaM}$. Consistent with these expectations, preincubation of AKAP79(1-153) with CaM in the presence of $\mathrm{Ca}^{2+}$ inhibited binding to $\mathrm{F}$-actin in the cosedimentation assay (Fig. $5 A$ ). This inhibitory effect of $\mathrm{CaM}$ was $\mathrm{Ca}^{2+}$ dependent and not observed in the absence of $\mathrm{Ca}^{2+}$ plus the chelator EGTA. Also in agreement with earlier work, previous phosphorylation of (1-153) with PKC (readily seen in electrophoretic mobility shifts) also inhibited F-actin cosedimentation (Fig. 5B). For the
MARCKS protein, PKC phosphorylation of the effector domain and $\mathrm{Ca}^{2+}-\mathrm{CaM}$ binding, both of which regulate targeting function, are competitive with one another (Aderem, 1992). To evaluate this possibility for AKAP79, we phosphorylated (1-153) with $\mathrm{PKC}$ in the presence of $\mathrm{Ca}^{2+}-\mathrm{CaM}$. PKC phosphorylation was significantly inhibited by $\mathrm{Ca}^{2+}-\mathrm{CaM}$ but not $\mathrm{CaM}$ and EGTA (Fig. 5C). These findings suggest that CaM binding to the AKAP basic targeting domain blocks access to sites phosphorylated by PKC. Thus, in cells it is possible that phosphorylation, multiple $\mathrm{CaM}$ binding events, or some combination of both processes acting through the three basic regions may regulate AKAP79 membrane/cytoskeletal interactions in response to $\mathrm{Ca}^{2+}$ signals.

\section{F-actin competes with phosphorylation and calmodulin binding in regulation of the AKAP79 targeting domain}

Because F-actin binding, phosphorylation, and $\mathrm{CaM}$ binding all converge on the same three basic regions, it is possible that when the targeting domain is bound to cortical actin in cells the basic regions may not be readily accessible for phosphorylation or CaM binding. Such a scenario would explain why in previous studies activation of PKC or CaM released very little AKAP79 from HEK-293 membrane fractions (Dell'Acqua et al., 1998). To test this idea biochemically, we varied the order of incubations of the (1-153) targeting domain with $\mathrm{PKC}$ or $\mathrm{Ca}^{2+}-\mathrm{CaM}$ and F-actin. In agreement with results presented above, under control conditions most of (1-153) sedimented with F-actin, and phosphorylation of (1-153) with PKC or incubation with $\mathrm{Ca}^{2}-\mathrm{CaM}$ before incubation with F-actin strongly inhibited this sedimentation (Fig. $5 D)$. In contrast, previous incubation of (1-153) with F-actin significantly attenuated the ability of $\mathrm{PKC}$ or $\mathrm{Ca}^{2+}-\mathrm{CaM}$ to then release the targeting domain from $\mathrm{F}$-actin, as seen in nearly equal distributions between the supernatants and pellets (Fig. 5D). Overall, these findings help confirm that the same basic regions that mediate membrane targeting and PI-4,5- $\mathrm{P}_{2}$ binding also regulate interactions with $\mathrm{F}$-actin.

\section{Glutamate regulation of dendritic F-actin and AKAP79/150 postsynaptic targeting}

On the basis of observations that AKAP79 targeting may be subject to regulation by $\mathrm{Ca}^{2+}$ signals as well as actin polymerization, we wanted to see whether postsynaptic localization of AKAP79/150 could be regulated by neuronal signaling pathways that elevate $\mathrm{Ca}^{2+}$ and reorganize the dendritic actin cytoskeleton. We treated cultured neurons with $50 \mu \mathrm{M}$ glutamate for 10 min and then fixed and stained to visualize localization of AKAP79/150 relative to F-actin, PSD-MAGUKs (including both PSD-95 and SAP97; pan-PSD-MAGUK antibody), and synapsin (Fig. 6). Similar glutamate treatments of hippocampal neurons have been shown to stimulate rapid AMPA receptor endocytosis and reorganization of dendritic F-actin (Halpain et al., 1998; Carroll et al., 1999b; Lissin et al., 1999; Beattie et al., 2000; Zhou et al., 2001). Consistent with earlier studies, exposure to glutamate led to a reorganization of F-actin in the dendrites manifested by loss of F-actin puncta on dendritic spines and increased actin filament staining along dendrite shafts (Fig. 6A) (Halpain et al., 1998). Also in agreement with previous work, treatment with glutamate did not drastically alter punctate distribution of the postsynaptic MAGUKs (Fig. 6B) or presynaptic terminals marked by synapsin (Fig. 6C) (Halpain et al., 1998). Glutamate treatment also caused a dramatic redistribution of 

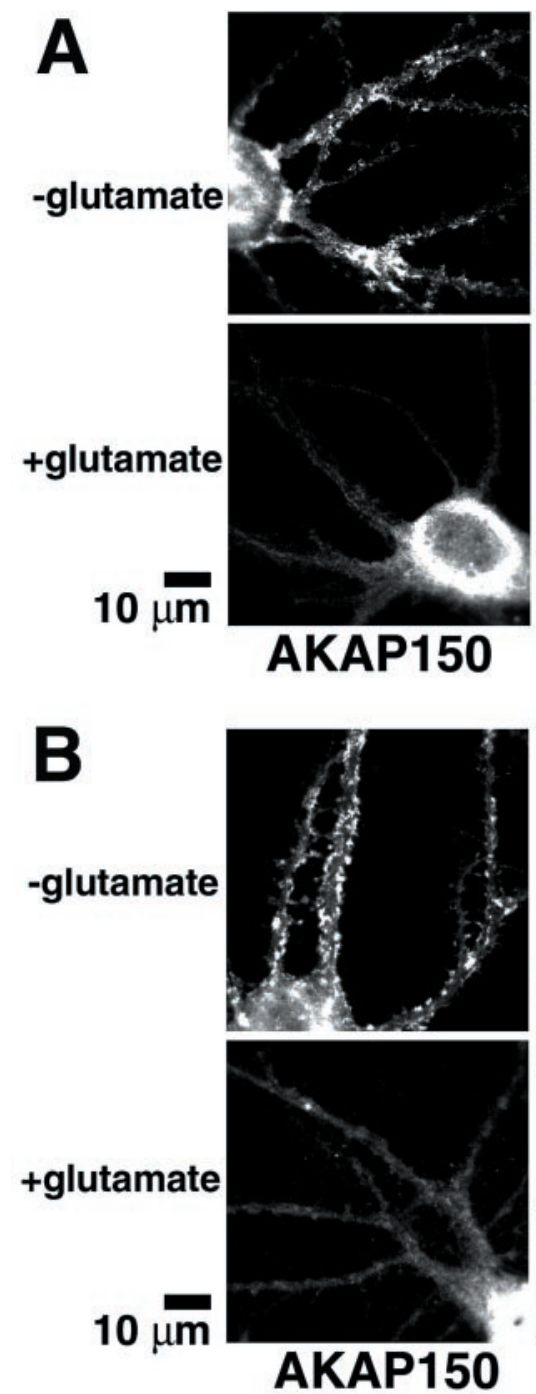

Figure 6. Glutamate regulation of AKAP79/150
postsynaptic localization and dendritic spine F-actin in hippocampal neurons. $A$, Redistribution of AKAP79/150 and reorganization of dendritic F-actin in response to glutamate in hippocampal neurons. $B$, Loss of AKAP79/150 colocalization with postsynaptic PSD-95 family MAGUK scaffolds after glutamate treatment. $C$, Glutamate regulation of AKAP79/150 localization near presynaptic terminals marked by synapsin. Neurons were treated for 10 min with $(+)$ or without $(-)$ glutamate $(50$ $\mu \mathrm{M}$ ) before staining for AKAP150 (red), F-actinphalloidin, PSD-95 family members (including PSD-95 and SAP97), or synapsin (all in green). The images shown are representative of neurons imaged in multiple $(>3)$ experiments for each condition.
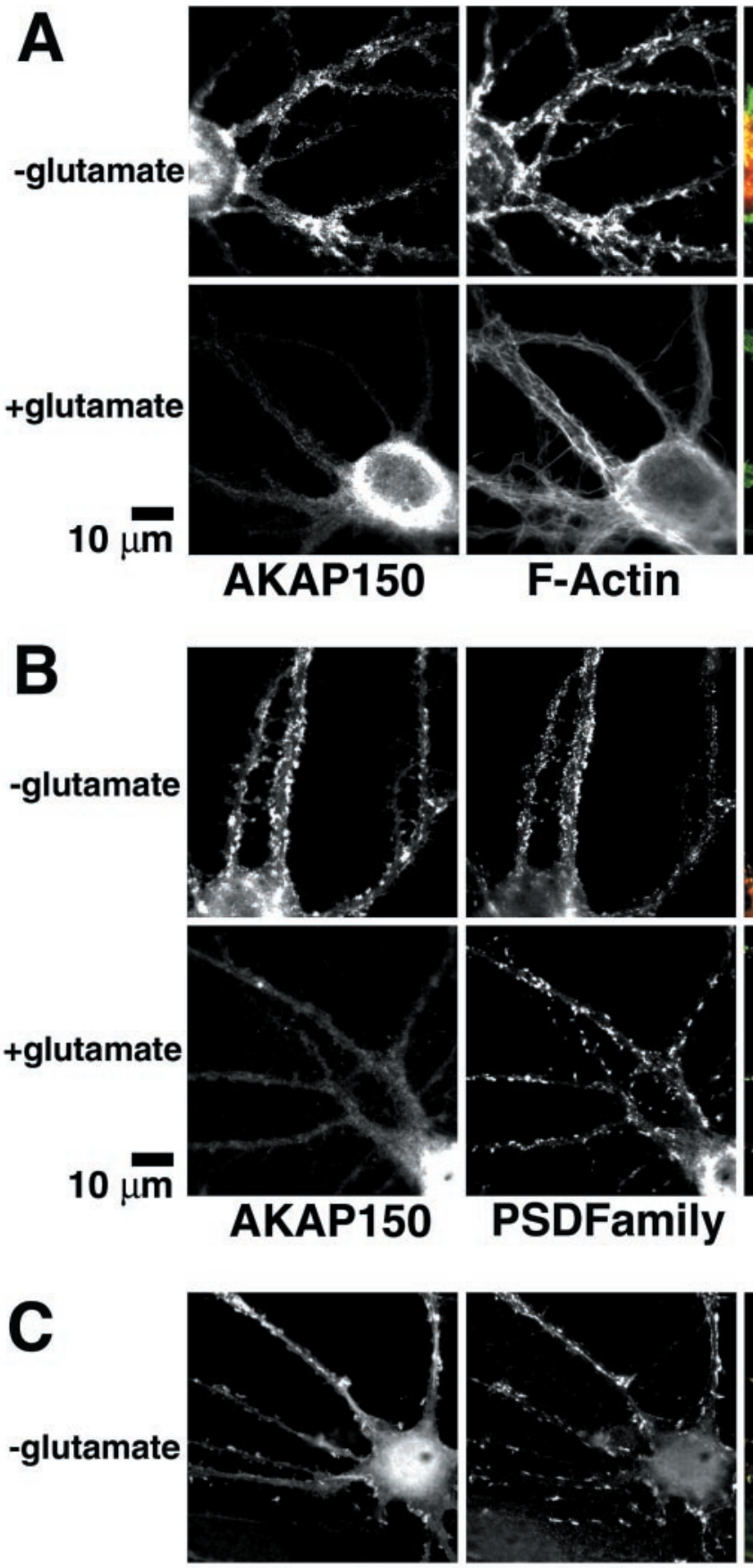

F-Actin
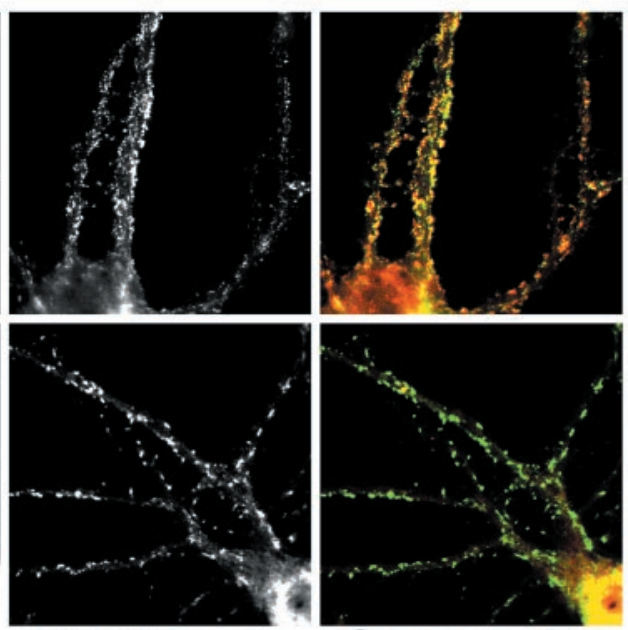

PSDFamily Composite

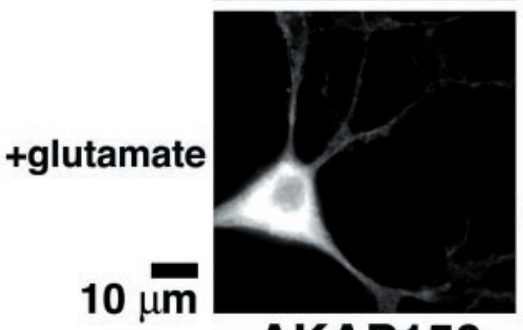

AKAP150
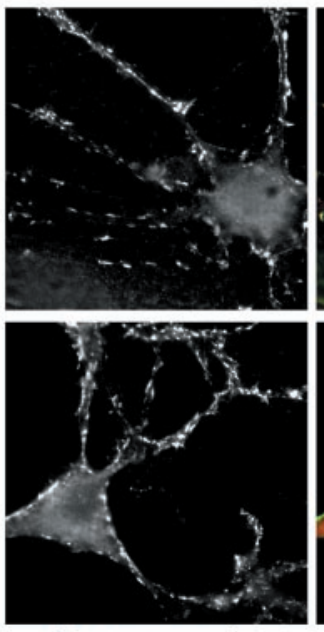

Synapsin
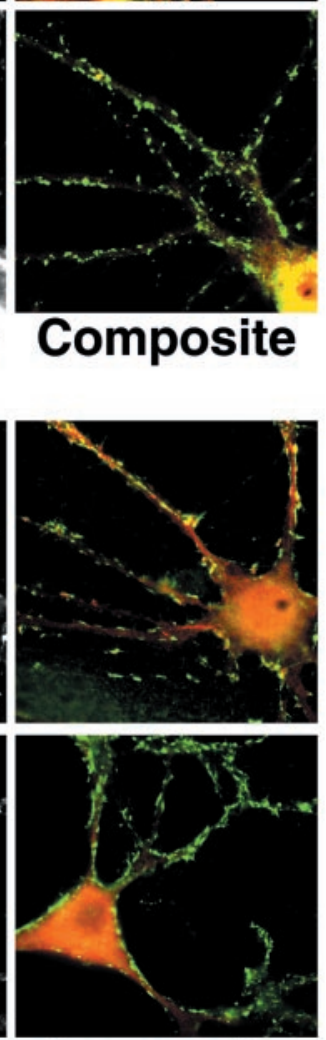

Composite
AKAP79/150 seen as loss of somatodendritic puncta, weak and diffuse staining in dendrite shafts, and increased fluorescence in the cytoplasm of the soma (Fig. 6A). This shift in localization of AKAP79/150 from dendrites to the soma was reflected in decreased dendritic fluorescence $(\mathrm{D} / \mathrm{T}=89 \pm 2 \%$ control, $n=6$;
$\mathrm{D} / \mathrm{T}=56 \pm 4 \%$ glutamate, $n=5)$ and increased somatic fluorescence $(\mathrm{S} / \mathrm{T}=131 \pm 6 \%$ control; $\mathrm{S} / \mathrm{T}=175 \pm 7 \%$ glutamate) that can be expressed together as a decreased ratio of mean dendritic to somatic fluorescence $(\mathrm{D} / \mathrm{S}=69 \pm 4 \%$ control; $\mathrm{D} / \mathrm{S}=$ $32 \pm 2 \%$ glutamate). Importantly, this glutamate-stimulated re- 
distribution of AKAP79/150 resulted in loss of colocalization with PSD-MAGUKs (Fig. 6B) (see below) and synapsin (Fig. 6C).

\section{Regulation of AKAP79/150 postsynaptic localization by NMDA receptor activation}

Both reorganization of dendritic spine F-actin and endocytosis of AMPA receptors can be triggered by activation of either NMDA or AMPA receptors alone (Halpain et al., 1998; Carroll et al., 1999b; Beattie et al., 2000; Lin et al., 2000; Man et al., 2000; Zhou et al., 2001). However, for regulation of some important forms of hippocampal LTD, $\mathrm{Ca}^{2+}$ influx through NMDA receptors is thought to be the key signaling event. In agreement with previous studies and as a positive control for NMDA receptor regulation of AMPA receptors, NMDA treatment clearly disrupted dendritic colocalization of GluR1 with PSD-95 (Fig. 7A). As shown above, in untreated neurons, AKAP79/150 showed significant codistribution with PSD-95 $\left(\mathrm{PSD}_{\mathrm{co}}=64 \pm 3 \% ; n=6\right)$, and treatment with glutamate led to rapid redistribution of AKAP79/ 150 from dendrites $(\mathrm{D} / \mathrm{S}=32 \pm 2 \%)$ manifested in loss of dendritic colocalization with PSD-95 $\left(\mathrm{PSD}_{\mathrm{co}}=8 \pm 3 \% ; n=5\right)$ (Fig. $7 B, C$ ). Brief preincubation of neurons in the presence of EGTA to chelate extracellular $\mathrm{Ca}^{2+}$ mostly prevented glutamatestimulated redistribution of AKAP79/150 from dendrites (D/S = $69 \pm 4 \%)$ and maintained colocalization with PSD-95 $\left(\mathrm{PSD}_{\mathrm{co}}=\right.$ $56 \pm 5 \% ; n=5)($ Fig. $7 C)$. Consistent with a predominant role for $\mathrm{Ca}^{2+}$ influx through NMDA receptors in this response, glutamate-stimulated redistribution of AKAP79/150 was blocked by the NMDA receptor antagonist AP-V (100 $\mu \mathrm{M} ; \mathrm{D} / \mathrm{S}=65 \pm$ $6 \%$; $\mathrm{PSD}_{\mathrm{co}}=62 \pm 4 \% ; n=6$ ), with no obvious additional effect seen with addition of the AMPA receptor antagonist CNQX (50 $\mu \mathrm{M} ; \mathrm{D} / \mathrm{S}=63 \pm 2 \% ; \mathrm{PSD}_{\mathrm{co}}=67 \pm 8 \% ; n=3$ ) (Fig. $7 B, C$ ). Furthermore, selective activation of NMDA receptors with $50 \mu \mathrm{M}$ NMDA was sufficient to cause redistribution of AKAP79/150 away from postsynaptic specializations $\left(\mathrm{D} / \mathrm{S}=40 \pm 4 \%\right.$; $\mathrm{PSD}_{\mathrm{co}}=$ $7 \pm 2 \% ; n=7)$ in an AP-V-sensitive manner $(\mathrm{D} / \mathrm{S}=64 \pm 4 \%$; $\mathrm{PSD}_{\mathrm{co}}=58 \pm 3 \% ; n=12$ ) (Fig. $7 B, C$ ). Thus, our conclusion is that NMDA receptor activation is both necessary and sufficient for activation of $\mathrm{Ca}^{2+}$-dependent signaling pathways regulating localization of AKAP79/150 to postsynaptic sites.

\section{Activation of the phosphatase calcineurin but not protein kinases is necessary for NMDA receptor regulation of AKAP79/150 targeting}

One potentially important target of $\mathrm{Ca}^{2+}$ influx that has been implicated in NMDA receptor regulation of dendritic spine F-actin and AMPA receptor localization is the $\mathrm{Ca}^{2+}$-activated phosphatase CaN-PP2B (Halpain et al., 1998; Beattie et al., 2000; Ehlers, 2000). It is possible that $\mathrm{CaN}$ stimulation of dendritic spine F-actin remodeling could have an active role in regulating the AKAP79/150 cytoskeletal linkage that maintains it at synapses. In agreement with this hypothesis, inhibition of $\mathrm{CaN}$ with either CsA (D/S $=47 \pm 4 \%$; $\left.\mathrm{PSD}_{\mathrm{co}}=46 \pm 4 \% ; n=8\right)$ or FK506 $\left(\mathrm{D} / \mathrm{S}=50 \pm 3 \% ; \mathrm{PSD}_{\mathrm{co}}=55 \pm 3 \% ; n=9\right)$ mostly prevented NMDA-regulated redistribution of AKAP79/150 when compared with untreated (control D/S $=57 \pm 3 \% ; \mathrm{PSD}_{\text {co }}=61 \pm 2 \%$; $n=14$ ) and NMDA-treated cells (NMDA D/S = $37 \pm 3 \%$; $\mathrm{PSD}_{\mathrm{co}}=4 \pm 1 \% ; n=10$ ) (Fig. $8 A, B$ ). No effects were seen in NMDA-treated cells with rapamycin, a drug that binds to immunophilins like CsA and FK506 but does not inhibit CaN (data not shown). Importantly, CaN is directly anchored to AKAP79/150 and thus may be optimally positioned to participate in regulation of the postsynaptic actin cytoskeleton in response to NMDA receptor activation. However, NMDA receptor $\mathrm{Ca}^{2+}$ signaling can also activate kinases such as PKC, CaMKII, and PKA (through $\mathrm{Ca}^{2+}$-regulated adenylyl cyclase). Furthermore, previous work and studies presented above show that PKC phosphorylation of the AKAP79 targeting domain can regulate PI-4,5- $\mathrm{P}_{2}$ and F-actin binding in vitro (Fig. 5) (Dell'Acqua et al., 1998). However, consistent with a dependence on phosphatases and not kinases, NMDA-mediated AKAP79/150 redistribution was insensitive to inhibition of $\mathrm{PKC}$ with chelerythrine-CHE $\left(\mathrm{D} / \mathrm{S}=34 \pm 3 \% ; \mathrm{PSD}_{\mathrm{co}}=5 \pm 2 \% ; n=5\right), \mathrm{CaMKII}$ with KN-62 $\left(\mathrm{D} / \mathrm{S}=29 \pm 2 \%\right.$ PSD $\left._{\mathrm{co}}=5 \pm 1 \%, n=3\right)$, or PKA with $\mathrm{H}-89\left(\mathrm{D} / \mathrm{S}=33 \pm 3 \%\right.$; $\left.\mathrm{PSD}_{\mathrm{co}}=5 \pm 2 \% ; n=4\right)$ (Fig. $\left.8 B\right)$.

\section{Reorganization of dendritic spine F-actin is necessary for NMDA receptor regulation of AKAP79/150 postsynaptic localization}

NMDA receptor activation of CaN-regulated F-actin remodeling could certainly control localization of AKAP79/150, as shown above by inhibition of actin polymerization with latrunculin disrupting AKAP79/150 postsynaptic targeting (Fig. 2). However, although F-actin reorganization accompanies redistribution of AKAP79/150 after glutamate or NMDA treatment (Fig. 6A) (data not shown), the AKAP does not appear to move directly with F-actin in these experiments. Nonetheless, it is possible that actin remodeling in response to NMDA receptor activation is a necessary first step allowing AKAP release from the PSD and lateral membrane diffusion followed by secondary redistribution (see below) away from the membrane. To test whether reorganization of F-actin is in fact necessary for NMDA receptorregulated redistribution of AKAP79/150, we pretreated neurons with jasplakinolide, a drug that stabilizes F-actin filaments and prevents NMDA-induced reorganization of dendritic spine F-actin (Halpain et al., 1998). Pretreatment with jasplakinolide for $2 \mathrm{hr}$ prevented $\left(\mathrm{D} / \mathrm{S}=59 \pm 3 \%\right.$; $\left.\mathrm{PSD}_{\text {co }}=46 \pm 4 \% ; n=7\right)$ NMDA-mediated redistribution of AKAP79/150 away from PSD-95 (D/S $=37 \pm 3 \%$; PSD $\left._{\text {co }}=4 \pm 1 \% ; n=10\right)$, similar to inhibition of $\mathrm{CaN}$ (see above), and nearly as well receptor block with AP-V (D/S = $64 \pm 4 \%$; $\mathrm{PSD}_{\mathrm{co}}=58 \pm 3 \% ; n=12$ ) (Fig. $8 A, B)$. Thus, remodeling of $\mathrm{F}$-actin in response to $\mathrm{CaN}$ activation is likely to untether the AKAP79/150 targeting domain from the postsynaptic cytoskeleton. These results taken together with the insensitivity to kinase inhibition are most consistent with a model in which F-actin reorganization makes the targeting domain accessible for subsequent $\mathrm{Ca}^{2+}-\mathrm{CaM}$ binding (Fig. 5D). CaM binding could then mediate secondary redistribution of AKAP79/ 150 away from the plasma membrane as well as prevent reassociation with dendritic F-actin after NMDA receptor activation. Unfortunately, this predicted secondary involvement of $\mathrm{CaM}$ binding in AKAP79/150 translocation cannot be investigated with $\mathrm{CaM}$ inhibitors because they also inhibit $\mathrm{CaN}$ activation.

\section{Inhibition of actin polymerization and NMDA receptor activation both regulate association of the AKAP79/ 150-PKA complex with PSD-MAGUKs}

Immunocytochemistry presented above shows that inhibition of actin polymerization and NMDA receptor activation both cause loss of AKAP79/150 from synapses, suggesting dissociation from PSD-MAGUK complexes. To independently confirm disassembly of AKAP79/150-MAGUK complexes, we immunoprecipitated AKAP79/150 from cell extracts prepared from neurons treated with latrunculin or NMDA and analyzed the immunoprecipitates by immunoblotting for AKAP150, PSD-MAGUKs (pan-PSD-MAGUK antibody), and PKA-RII $\beta$ subunits. The levels of AKAP79/150, PSD-MAGUKs, and PKA-RII $\beta$ were 


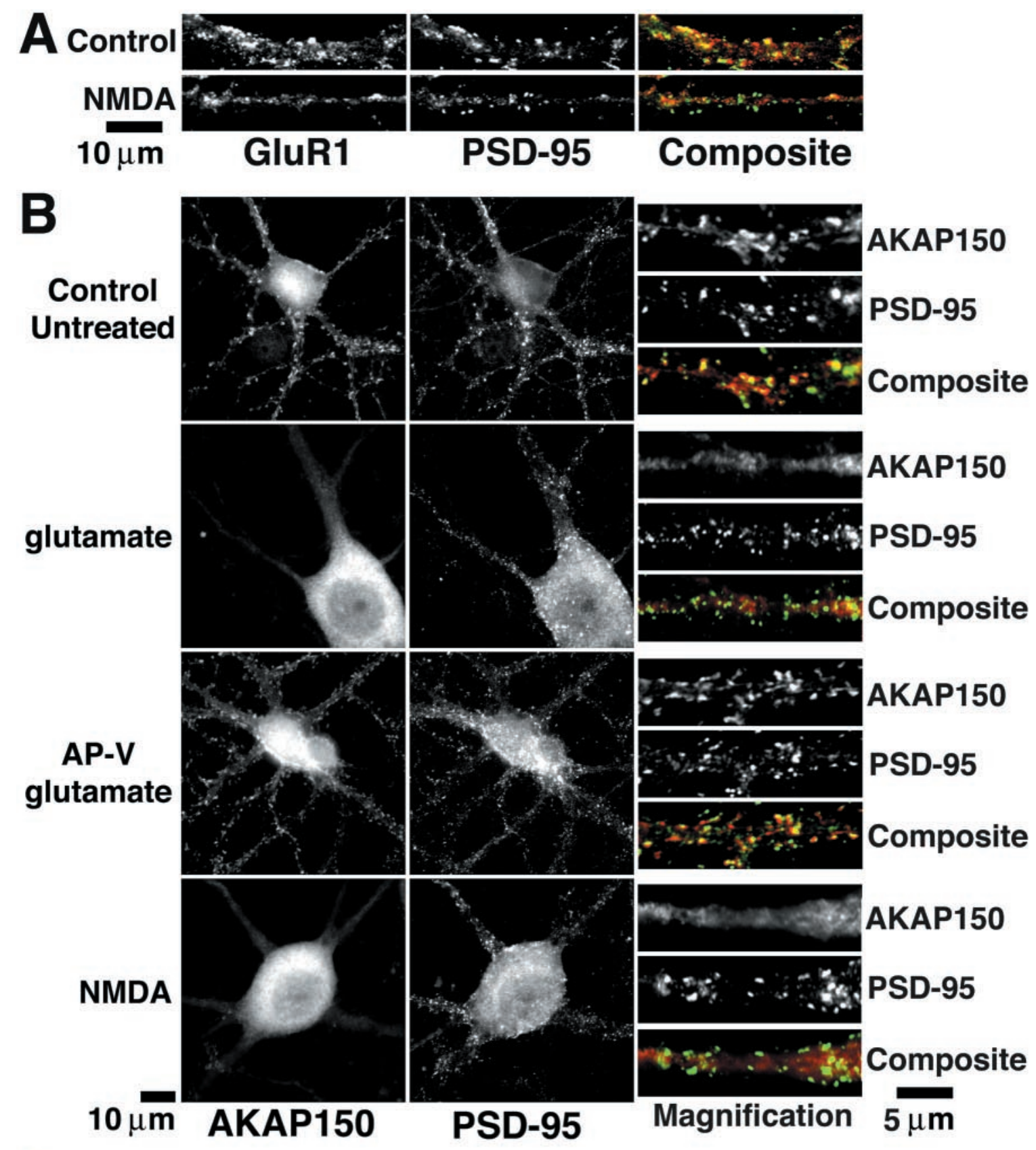

C

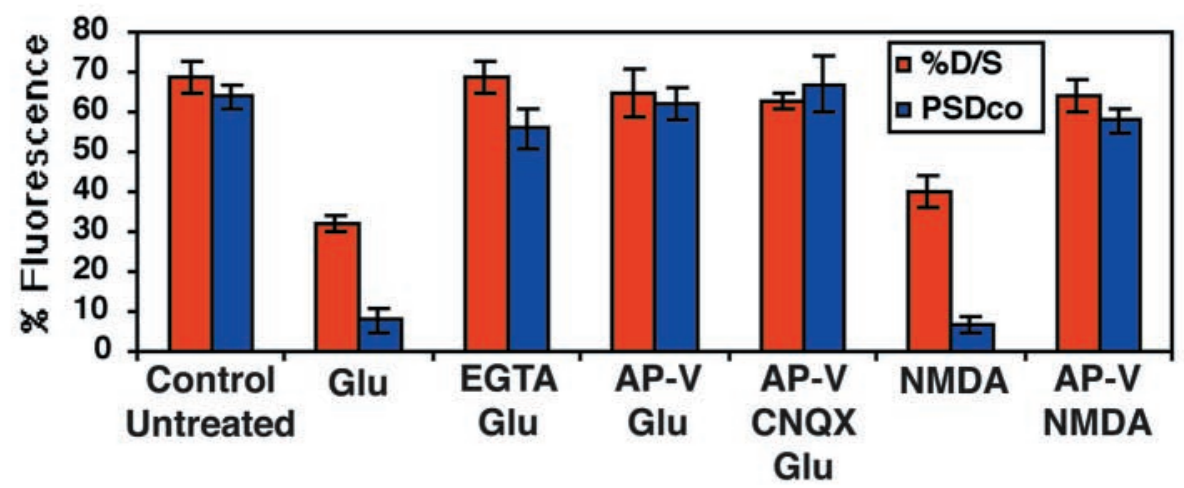

Figure 7. Regulation of AKAP79/150 postsynaptic localization by NMDA receptor activation. A, Loss of GluR1 AMPA-receptor (red) dendritic colocalization with PSD-95 (green) in NMDA-treated neurons. B, Loss of AKAP79/150 (red) colocalization with PSD-95 (green) in glutamate or NMDA-treated neurons. Neurons were treated for $10 \mathrm{~min}$ with glutamate $(50 \mu \mathrm{M})$ or NMDA $(50 \mu \mathrm{M})$. Glutamate regulation of AKAP79/150 targeting was blocked by the NMDAR antagonist AP-V (100 $\mu \mathrm{M}, 15 \mathrm{~min}$ pretreatment). Large panels show AKAP150 and PSD-95 (Figure legend continues.) 
essentially the same in cell extracts prepared from untreated control neurons and latrunculin- or NMDA-treated neurons, indicating that there was no significant proteolytic loss of these proteins resulting from the treatments (Fig. 9A,B). Roughly equal amounts of AKAP150 and PKA-RII $\beta$ were detected in AKAP150 immunoprecipitates from control and latrunculin- or NMDA-treated neurons, indicating that the AKAP-PKA complex is still intact after these treatments (Fig. 9A,B). In contrast, PSD-MAGUK proteins, which are readily seen coprecipitating with AKAP150 from control neurons, are not detectable in AKAP150 precipitates from latrunculin- or NMDA-treated neurons (Fig. 9A,B), even after long exposures (data not shown). Thus, reorganization of $\mathrm{F}$-actin caused by either latrunculin treatment or NMDA receptor activation leads not only to altered subcellular targeting of AKAP79/150 seen by immunocytochemistry but also to disruption of AKAP-MAGUK complexes detected biochemically. Disruption of AKAP-MAGUK complexes should in turn break AKAP79/150 linkage to glutamate receptors. Although we were unable to address this question directly by coprecipitation because of the small amounts of extract obtained from cultured neurons, our immunocytochemistry supports this prediction. Latrunculin A and NMDA both trigger loss of AKAP79/150 and GluR1 colocalization with PSD-95, but GluR1 remains punctate, consistent with trafficking to endosomes (Ehlers, 2000), whereas AKAP79/150 becomes more diffuse and untargeted (Figs. 2, 7).

\section{NMDA receptor regulation of AKAP79/150 postsynaptic targeting and redistribution of PKA and $\mathrm{CaN}$}

An additional prediction that is supported by our results showing equal coprecipitation of AKAP150 and PKA-RII $\beta$ after latrunculin or NMDA treatment is that anchored PKA may be redistributing from dendritic spines in a complex with AKAP79/150. As shown above (Fig. 2), in untreated cells PKA-RII $\beta$ showed extensive punctate codistribution with AKAP79/150 on dendritic spines $\left(150-\mathrm{RII}_{\mathrm{co}}=68 \pm 6 \% ; n=7\right)($ Fig. $10 A)$. PKA-RII $\beta$ also displayed independent localization in cell bodies and proximal dendritic shafts, probably reflecting anchoring to other AKAPs in those locations (Fig. 10A). After treatment with glutamate, RII $\beta$ and AKAP79/150 became diffuse and punctate dendritic spine colocalization was lost, with insufficient puncta for either protein remaining for quantitation (Fig. 10 $\mathrm{A}$ ). However, in response to glutamate, dendritic fluorescence decreased for both AKAP79/ 150 (control D/T $=83 \pm 2 \%, n=6$; glutamate $\mathrm{D} / \mathrm{T}=51 \pm 2 \%$, $n=5$ ) and $\mathrm{RII} \beta$ (control D/T $=67 \pm 2 \%$; glutamate $\mathrm{D} / \mathrm{T}=54 \pm$ $2 \%$ ) (Fig. $10 A$ ). After all treatments, the prominent localization of RII $\beta$ in the soma and proximal dendritic shafts was unaltered, suggesting that NMDA receptor activation selectively regulated localization of a pool of PKA bound to AKAP79/150. Importantly, the NMDA receptor antagonist AP-V inhibited the effects of glutamate on RII $\beta$ and AKAP79/150 localization (RII D/T =
$77 \pm 4 \%$; AKAP150 D/T $=86 \pm 2 \%)$ and spine colocalization $\left(150-\mathrm{RII}_{\mathrm{co}}=50 \pm 7 \% ; n=4\right)($ Fig. $10 \mathrm{~A})$.

From the results presented in Figure 8, redistribution of AKAP79/150 involves activation of CaN. Anchoring of the $\mathrm{CaN}$ A, B holoenzyme to AKAP79/150 is mediated through binding of catalytic CaNA subunit in a manner that noncompetitively inhibits phosphatase activity (Coghlan et al., 1995; Dell'Acqua et al., 1998; Kashishian et al., 1999). Thus, we wanted to see whether the AKAP-CaN interaction might be regulated by the NMDA receptor. Unfortunately, our efforts to look for release of $\mathrm{CaN}$ from AKAP79/150 by immunoprecipitation were unsuccessful because of limitations of $\mathrm{CaN}$ antibody sensitivities and small amounts of extracts obtained from cultured neurons (data not shown). Nonetheless, regulation of the CaN-AKAP79/150 interaction by NMDA receptor activation might be manifested in changes in the dendritic localization of $\mathrm{CaN}$ relative to the AKAP. Others have observed changes in the pattern of CaNA subunit staining in hippocampal neurons after NMDA and glutamate treatments similar to those used here (Halpain et al., 1998). In untreated neurons, $\mathrm{CaNB}$ and AKAP79/150 showed punctate colocalization $\left(150-\mathrm{CaN}_{\mathrm{co}}=58 \pm 2 \% ; n=6\right)$ on dendritic spines (Fig. $10 \mathrm{~B}$ ); however, $\mathrm{CaN}$ was distributed more extensively throughout the cytoplasm of the cell body. Treatment of neurons with glutamate disrupted punctate dendritic spine colocalization of AKAP79/150 and CaNB $\left(150-\mathrm{CaN}_{\mathrm{co}}=3 \pm 1 \% ; n=8\right)$, with the AKAP redistributing to a diffuse localization in dendrites and the soma as observed above (control D/T $=74 \pm 3 \%, \mathrm{D} / \mathrm{S}=50 \pm$ $3 \%, \mathrm{~S} / \mathrm{T}=149 \pm 7 \%$; glutamate $\mathrm{D} / \mathrm{T}=42 \pm 2 \%, \mathrm{D} / \mathrm{S}=22 \pm$ $1 \%, \mathrm{~S} / \mathrm{T}=190 \pm 8 \%$ ) (Fig. $10 B)$. AP-V pretreatment inhibited the glutamate-regulated redistribution of AKAP79/150 (D/T = $66 \pm 3 \%, \mathrm{D} / \mathrm{S}=40 \pm 3 \%, \mathrm{~S} / \mathrm{T}=168 \pm 6 \%$ ) relative to $\mathrm{CaNB}$ $\left(150-\mathrm{CaN}_{\mathrm{co}}=44 \pm 3 \% ; n=6\right)$, thus confirming involvement of NMDA receptors (Fig. 10B). In response to glutamate, punctate CaNB staining certainly decreased $(\sim 45 \%)$; however, unlike AKAP and PKA, overall CaNB staining remained distributed in dendrites and did not concentrate any more in soma in glutamatetreated $(\mathrm{D} / \mathrm{T}=64 \pm 4 \%, \mathrm{D} / \mathrm{S}=41 \pm 4 \%, \mathrm{~S} / \mathrm{T}=155 \pm 7 \%)$ versus untreated neurons $(\mathrm{D} / \mathrm{T}=67 \pm 4 \%, \mathrm{D} / \mathrm{S}=43 \pm 3 \%$, $\mathrm{S} / \mathrm{T}=159 \pm 8 \%$ ) (Fig. $10 B$ ). Disruption of AKAP79/150-CaN colocalization on dendritic spines without coincident $\mathrm{CaN}$ movement from dendrites to the soma could be indicative of $\mathrm{CaN}$ release from the AKAP. However, an alternative explanation is that $\mathrm{CaN}$ is simply in excess of AKAP in dendrites. Nonetheless, NMDA receptor regulation of AKAP79/150-PKA localization (Fig. $10 A$ ) is also accompanied by distinct changes in colocalization with CaN (Fig. 10B).

\section{DISCUSSION}

We show that AKAP79/150 localization to excitatory synapses requires the actin cytoskeleton. Postsynaptic cytoskeletal tethering of AKAP79/150 is likely to involve N-terminal basic regions that bind F-actin, acidic phospholipids and target to membrane

$\leftarrow$

(Figure legend continued.) localization separately in both dendrites and soma. The Magnification panels show AKAP150, PSD-95, and Composite images for localization in single dendrites to show details better. $C$, Quantitation of AKAP79/150 mean fluorescence intensity distributions between dendrites and somata $(\% D / S$, red $)$ and integrated colocalization with PSD-95 $\left(P S D_{c o}\right.$, blue $)$ from multiple experiments for the treatment conditions in $B$ as well additional conditions described below. See Results and Materials and Methods for additional details. Glutamate regulation of AKAP79/150 targeting was also blocked by chelation of extracellular $\mathrm{Ca}^{2+}$ with EGTA $(5 \mathrm{mM})$. In the presence of glutamate and AP-V, no additional effect of the AMPAR antagonist CNQX $(50 \mu \mathrm{M}, 15 \mathrm{~min}$ pretreatment) was seen. Selective activation of AMPA receptors with $50 \mu \mathrm{M}$ AMPA (in the presence of $100 \mu \mathrm{M}$ AP-V), although having some effect on AKAP79/150 postsynaptic localization, did not result in a dramatic redistribution as seen with NMDA or glutamate (data not shown). NMDA regulation of AKAP79/150 targeting was also blocked by the NMDAR antagonist AP-V (100 $\mu \mathrm{M}, 15$ min pretreatment). 
Figure 8. Activation of the protein phosphatase-2B calcineurin and reorganization of F-actin are necessary for NMDA receptor regulation of AKAP79/ 150 postsynaptic localization. $A$, Activation of $\mathrm{CaN}$ and reorganization of F-actin are necessary for NMDA regulation of AKAP79/150 localization. Neurons were left untreated or pretreated with the indicated CaN-PP2B phosphatase inhibitors CsA $(1 \mu \mathrm{M}, 30 \mathrm{~min})$ or FK506 $(1 \mu \mathrm{M}, 30$ min), the actin-stabilizing drug jasplakinolide $(2 \mu \mathrm{M}, 2 \mathrm{hr})$, or the NMDA receptor antagonist AP-V $(100 \mu \mathrm{M}, 30$ $\min )$ before NMDA treatment $(50 \mu \mathrm{M}, 10$ $\mathrm{min})$. The neurons were then fixed and stained for AKAP79/150 (red) and PSD-95 (green). Large panels show AKAP150 and PSD-95 localization separately in both dendrites and soma. The Magnification panels show AKAP150, PSD-95, and Composite images for localization in single dendrites to show details better. $B$, Calcineurin protein phosphatase but not protein kinase activity is necessary for NMDA regulation of AKAP79/150 localization. Quantitation tensity distributions between dendrites and somata $(\% D / S$, red $)$ and integrated colocalization with PSD-95 (PSD $D_{c o}$, blue) from multiple experiments for the treatment conditions in $A$ as well additional conditions described below are shown. See Results and Materials and Methods for additional details. Neurons were also pretreated for $30 \mathrm{~min}$ with the indicated kinase inhibitors for PKA, H-89 (500 $\mathrm{nM})$; PKC, CHE (10 $\mu \mathrm{M})$; or CaMKII, $(50 \mu \mathrm{M}, 10 \mathrm{~min})$. Pretreaments with casein kinase II inhibitor (DRB, 50-100 $\mu \mathrm{M})$ or multiple kinase inhibitors (H-89, CHE, KN-62, DRB) had no effects on AKAP150 redistribution in NMDAtreated cells (data not shown). of AKAP79/150 mean fluorescence in$\mathrm{KN}-62(5 \mu \mathrm{M})$ before NMDA treatment

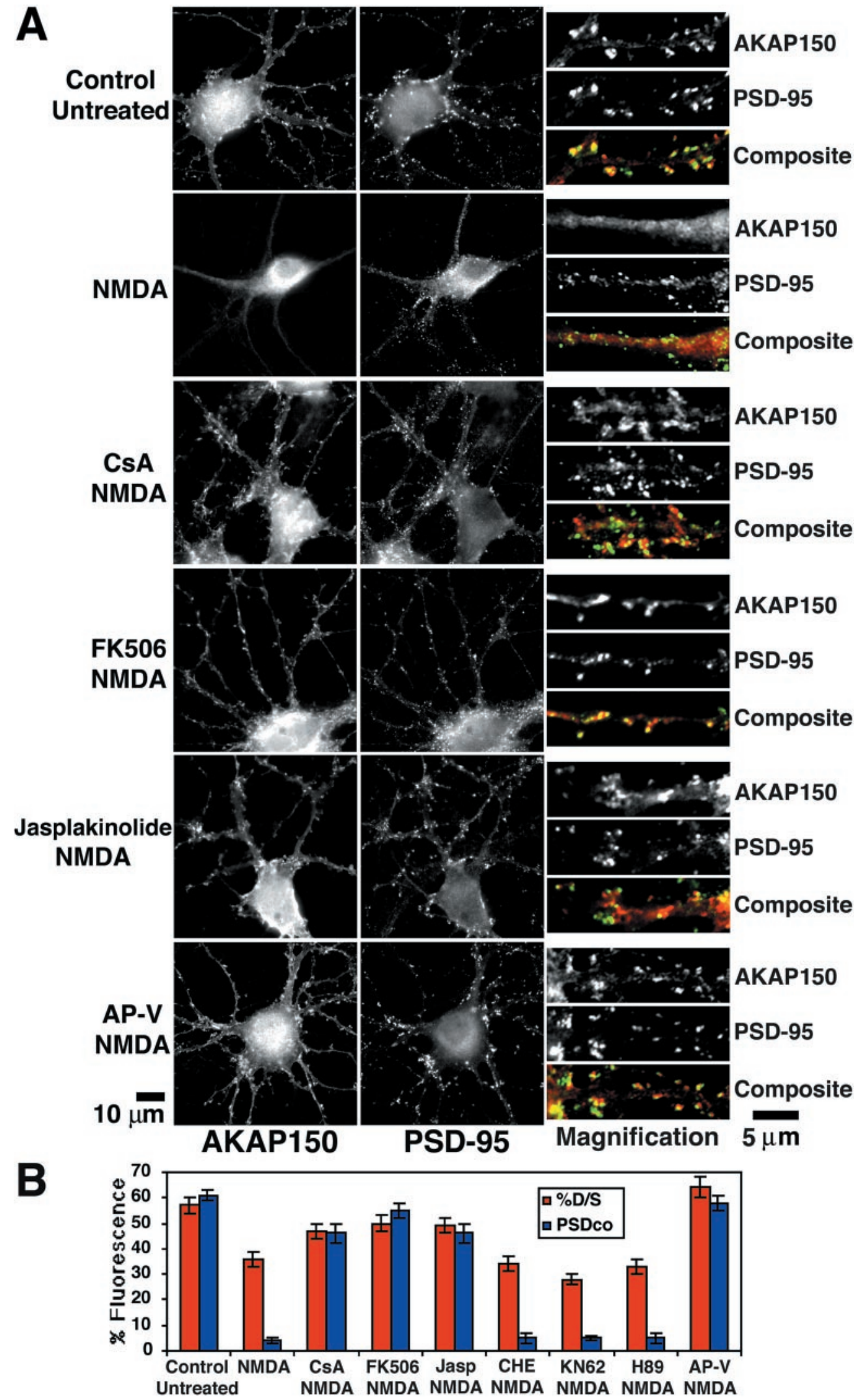

ruffles in COS7 cells and dendritic spines in neurons. Binding of this targeting domain to both F-actin and acidic lipids, linking plasma membrane to cortical actin, could easily explain how AKAP79, like MARCKS, is enriched in membrane ruffles. In particular, PI-4,5- $\mathrm{P}_{2}$, one of the primary acidic phospholipids that the AKAP79 targeting and MARCKS effector domains bind, is highly enriched with actin as well as AKAP79 in ruffles (Dell'Acqua et al., 1998; Tall et al., 2000; Wang et al., 2001). 


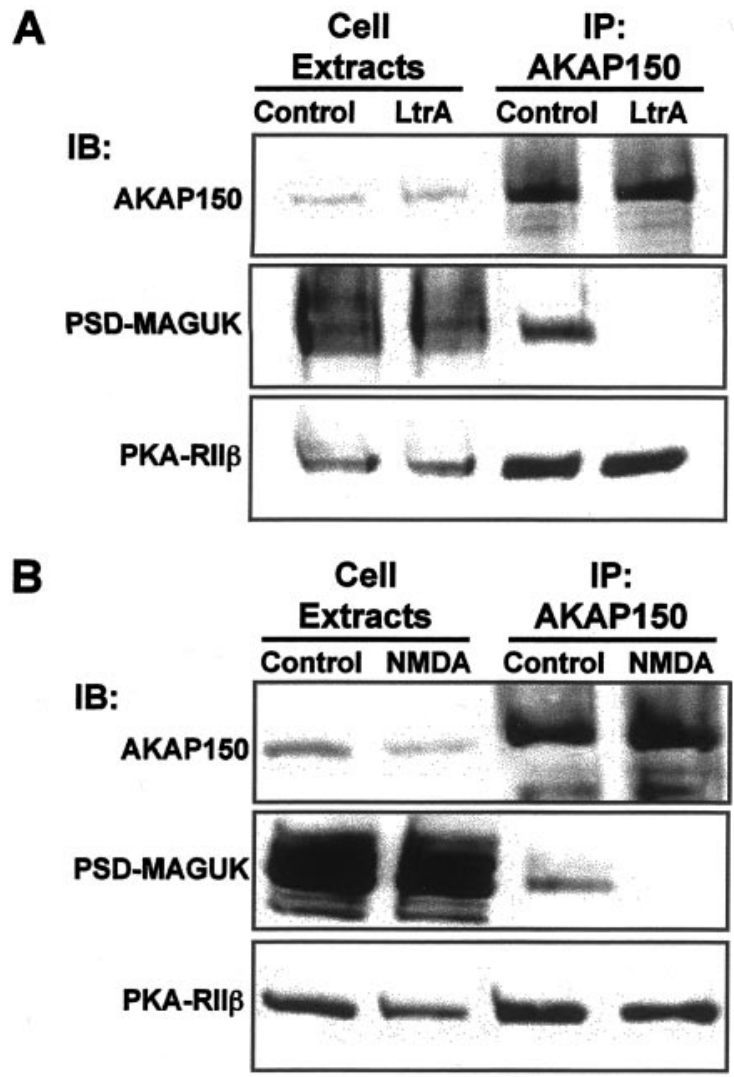

Figure 9. Regulation of AKAP79/150-PKA association with PSDMAGUKs by inhibition of actin polymerization and NMDA receptor activation. $A$, Inhibiting $\mathrm{F}$-actin polymerization with latrunculin $\mathrm{A}$ disrupts association of AKAP79/150 with PSD-MAGUKs but not PKA in complexes isolated from hippocampal neuron cell extracts. $B$, NMDA receptor activation disrupts association of AKAP79/150 with PSDMAGUKs but not PKA in complexes isolated from hippocampal neuron cell extracts. Neurons grown at high density on Petri plates were either untreated for control conditions or treated with latrunculin $\mathrm{A}(+\operatorname{Ltr} A ; 5$ $\mu \mathrm{M}, 4 \mathrm{hr})(A)$ or NMDA $(50 \mu \mathrm{M}, 10 \mathrm{~min})(B)$ before harvesting and lysis to prepare whole-cell extracts. AKAP79/150 was then immunoprecipitated (IP: $A K A P 150)$ from Triton X-100-soluble fractions prepared from these extracts. The immunoprecipitates and whole-cell extracts were then analyzed by immunoblotting (IB:) for AKAP150, PSD-MAGUK family members, and the PKA-RII $\beta$ regulatory subunit as indicated. The data shown are representative of three experiments done on two to four samples for each condition.

Earlier studies of AKAP79/75 localization in HEK-293 cells suggested that cortical F-actin was not necessary for membrane targeting (Li et al., 1996; Dell'Acqua et al., 1998). Indeed, AKAP79 can bind to phospholipid vesicles supporting direct membrane association (Dell'Acqua et al., 1998). In fact, even in our COS7 studies after cytochalasin D treatment, we see diff use plasma membrane localization as well as more prominent intracellular membrane localization of AKAP79 consistent with phospholipid binding. However, although previous studies in HEK293 cells also detected AKAP79/75 membrane targeting after cytochalasin D treatment, they did not explore actin requirements for more specific localization to ruffles. Failure to appreciate the F-actin dependence of AKAP79 localization in earlier studies might also be related to differences in morphology between COS7 versus HEK-293 cells, the latter of which are more round and less ruffled.

Our current findings clearly show that retention of AKAP79/
150, PKA, and $\mathrm{CaN}$ at specialized actin-rich membrane structures in both COS7 cells and neurons depends on F-actin. Furthermore, we find that AKAP79/150 postsynaptic scaffolding interactions with PSD-MAGUKs depends first on proper AKAP membrane/F-actin targeting. We find that NMDA receptor activation, which reorganizes dendritic actin, causes a rapid redistribution of the AKAP79/150-PKA complex away from PSDMAGUKs. Analysis of this AKAP79/150 regulation revealed a dependency on $\mathrm{Ca}^{2+}$ influx that is likely to involve activation of a previously characterized pathway involving the phosphatase $\mathrm{CaN}$ and F-actin remodeling (Halpain et al., 1998).

\section{Similar mechanisms of AKAP79/150 and AMPA receptor synaptic localization}

Interestingly, the targeting mechanisms that we have elucidated for AKAP79/150 are remarkably similar to those investigated by others for AMPA receptors that can be linked to the AKAP through SAP97 (Colledge et al., 2000). For example, AKAP79/ 150 and AMPA receptor postsynaptic localization are both disrupted by inhibiting actin polymerization with latrunculin and maintained by stabilizing F-actin with jasplakinolide (Allison et al., 1998, 2000; Shen et al., 2000; Zhou et al., 2001). AMPAGluR1 and SAP97 both bind to $4.1 \mathrm{~N} / \mathrm{G}$-actin binding proteins, providing possible linkage to the cytoskeleton (Lue et al., 1994, 1996; Wu et al., 1998; Shen et al., 2000). However, our findings suggest that AKAP79/150 might provide another point of attachment to spine actin for SAP97-GluR1 complexes. Importantly, recruitment of AMPA receptors to synapses during LTP in response to NMDA receptor and CaMKII activation requires the GluR1 C-terminal PDZ-binding site recognized by SAP97 (Leonard et al., 1998; Hayashi et al., 2000; Passafaro et al., 2001; Shi et al., 1999, 2001) as well as F-actin (Kim and Lisman, 1999; Krucker et al., 2000). Thus, AKAP79/150 binding to F-actin and SAP97 may play a role in synaptic delivery of AMPA-GluR1 receptors, a process that seems to correlate with PKA phosphorylation (Ehlers, 2000; Lee at al., 2000).

AKAP79/150 is also linked to NMDA receptors through PSD-95 binding to NR2A/B (Colledge et al., 2000). However, although PSD-95 and NMDA receptors are also linked to the actin cytoskeleton, synaptic localization of PSD-95 and NMDA receptors does not require F-actin and is not rapidly regulated by glutamate (Allison et al., 1998, 2000; Carroll et al., 1999b; Lissin et al., 1999). Nonetheless, AKAP79/150 complexes with PSD-95 could be important for regulating not only NMDA receptors but also nearby AMPA receptors independent of linkage through SAP97. Indeed, mice lacking functional PSD-95, although having normal NMDA receptor localization, exhibit abnormal hippocampal synaptic plasticity characterized by enhanced LTP and no LTD, indicating altered coupling to pathways regulating AMPA receptors (Migaud et al., 1998). One way in which PSD-95 may regulate AMPA receptor localization is through PDZ binding to AMPA receptor-associated Stargazin (Chen et al., 2000; El-Husseini et al., 2000b). Thus, the AKAP79/150 scaffold might also be linked to AMPA receptors through PSD-95.

\section{NMDA receptor regulation of AKAP79/150 and AMPA receptor localization by signaling pathways shared with LTD}

Importantly, we demonstrate that association of AKAP79/150PKA with PSD-MAGUKs is regulated by NMDA receptor signaling pathways that also control synaptic targeting of AMPA receptors. Work by others has implicated NMDA activation of $\mathrm{CaN}$ in the regulation of endocytosis and dephosphorylation of 
Figure 10. NMDA receptor activation regulates dendritic spine localization of PKA and CaN with AKAP79/150. A, NMDA receptor regulation of PKARII $\beta$ and AKAP79/150 localization. $B$, Disruption of dendritic spine colocalization of CaNB and AKAP79/150 in response to NMDA receptor activation. Neurons (2-3 weeks old) were untreated, pretreated with antagonist AP-V $(100 \mu \mathrm{M}, 30 \mathrm{~min})$, or treated with glutamate $(50 \mu \mathrm{M}, 10 \mathrm{~min})$ as indicated. Control untreated and treated neurons were stained for AKAP79/150 (red) and either PKA-RII $\beta$ regulatory subunits (green) in $A$ or CaNB (green) in $B$. The smaller panels are magnifications of dendrites. See Results for quantitation.
A
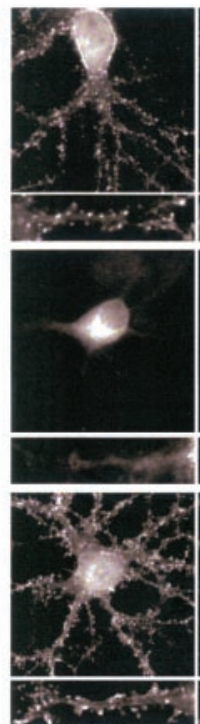

AKAP150
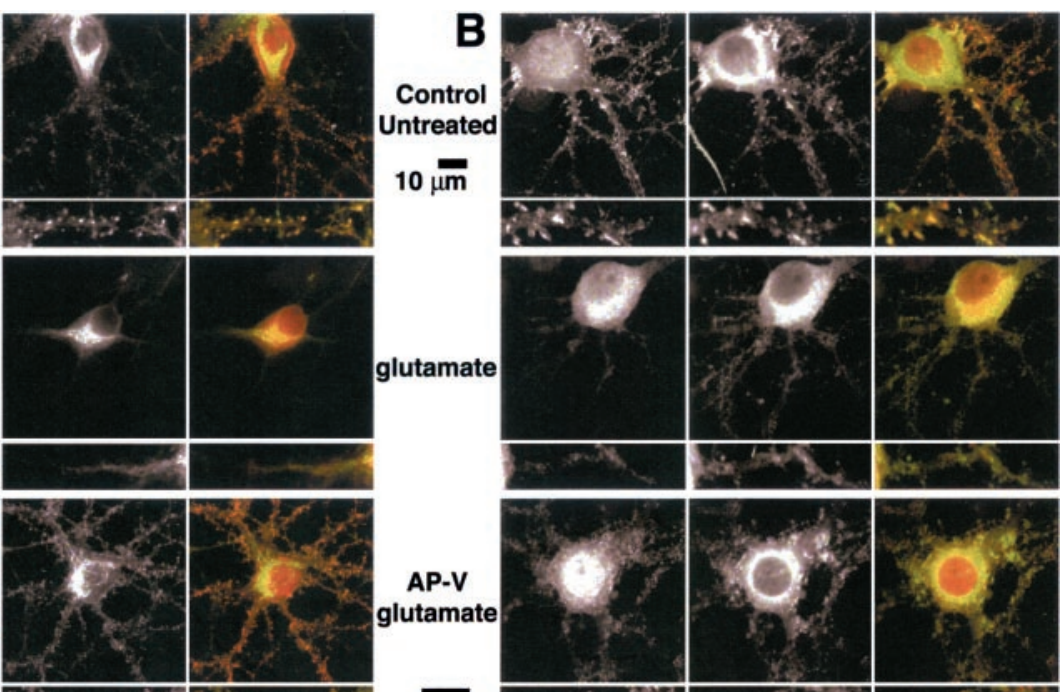

AP-V
glutama
$10 \mu \mathrm{m}$

PKA-RII Composite

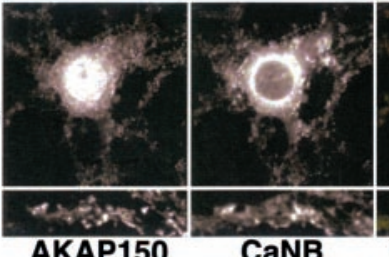

AKAP150

CaNB
Composite

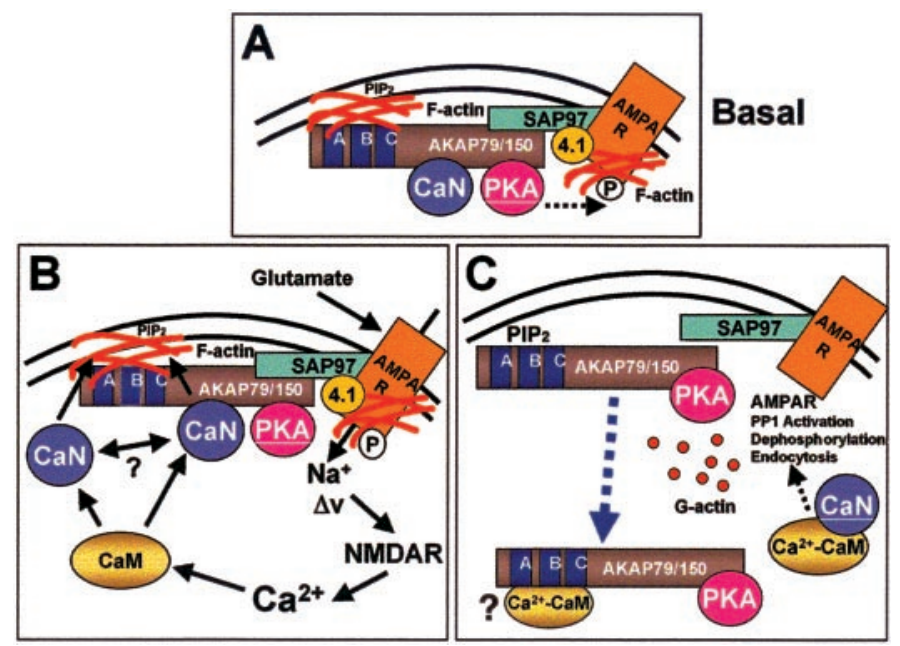

Figure 11. Possible relationships in regulation of the AKAP79/150 scaffold and AMPA receptors by NMDA receptor signaling pathways. $A-C$, Implications for LTD: a model of possible roles for NMDA receptors and $\mathrm{CaN}$-mediated F-actin reorganization in regulation of AKAP79/150 localization and AMPA receptor phosphorylation and localization. For the sake of simplicity, only AMPA receptor-SAP97-AKAP79/150 complexes are shown. Nearby NMDA receptor-PSD-95-AKAP79/150 complexes are also likely to participate in these signaling events. See Discussion for details.

PKA-phosphorylated AMPA receptors through mechanisms thought to be shared with LTD (Carroll et al., 1999a; Beattie et al., 2000; Ehlers, 2000). In Figure 11, we summarize our findings for regulation of AKAP79/150 localization and speculate how they might relate to AMPA receptor modulation. Under basal conditions, AKAP79/150-SAP97-AMPA receptor complexes may be stabilized at the synaptic membrane by interactions of the AKAP targeting domain and GluR1-SAP97-4.1 complexes with F-actin (Fig. 11A). Any CaN present in these receptor complexes would be inhibited at least partially by the AKAP (Coghlan et al., 1995; Dell'Acqua et al., 1998; Kashishian et al., 1998). In this context, PKA activity anchored to AKAP79/150 may be sufficient to maintain basal phosphorylation of AMPA-GluR1 on Ser 845 (Lee et al., 2000) (Fig. 11A). However, this balance of PKA and
$\mathrm{CaN}$ activity may be quite dynamic, as seen in studies showing that disruption of PKA anchoring with AKAP inhibitor peptides in hippocampal neurons decreases AMPA receptor activity through CaN-PP1 pathways (Tavalin et al., 2002). In addition, AKAP79-anchored PKA and $\mathrm{CaN}$ have been shown to bidirectionally regulate activity and phosphorylation of SAP97linked GluR1 on Ser845 in transfected cells in an LTD-like manner (Colledge et al., 2000; Tavalin et al., 2002). As mentioned above, AKAP79/150 is also present in membrane complexes with NMDA receptors, PSD-95, and F-actin that could serve similar functions for regulation of AMPA receptors not linked to SAP97 (Sans et al., 2001).

After treatment of neurons with glutamate/NMDA, influx of $\mathrm{Ca}^{2+}$ through NMDA receptors would trigger activation of CaM and $\mathrm{CaN}$, which may be activated to a low level bound to the AKAP, be in excess of the AKAP, or be released from the AKAP (Fig. $11 B$ ). In any case, CaN activation leading to local reorganization of F-actin would untether the AKAP from the cytoskeleton, thereby disrupting AKAP complexes with MAGUKs, including SAP97 and PSD-95 (Fig. 11C). This untethering may allow lateral diffusion and then release of the AKAP from the membrane and PI-4,5- $\mathrm{P}_{2}$ through a secondary process that could involve $\mathrm{Ca}^{2+}$ $\mathrm{CaM}$ binding to the targeting domain (Dell'Acqua et al., 1998) (Fig. 11C). Loss of AKAP79/150-anchored PKA from the synapse, like disruption of PKA anchoring with inhibitor peptides, would favor dephosphorylation events mediated by $\mathrm{CaN}$ and synapseanchored PP1 (Mulkey et al., 1994; Rosenmund et al., 1994; Blitzer et al., 1998; Morishita et al., 2001; Tavalin et al., 2002). Moreover, movement of the inhibitory AKAP would favor increased synaptic CaN activation. The actions of phosphatases on GluR1 itself, as well as endocytic proteins such as dynamin, might favor GluR1Ser845 dephosphorylation coincident with recruitment of AMPA receptors to clathrin-coated pits for removal by endocytosis (Fig. 11C) (Carroll et al., 1999b; Lai et al., 1999; Lin et al., 2000; Man et al., 2000; Beattie et al., 2000; Ehlers, 2000).

A very similar sequential model of untethering from actin followed by endocytosis has been proposed by others to explain the mechanism of loss of AMPA receptors from synapses in response to glutamate/NMDA or latrunculin treatment of cultured neurons (Zhou et al., 2001). Although the mechanistic links 
between $\mathrm{CaN}$ activation and F-actin reorganization in AMPA receptor endocytosis are not completely clear [see also Beattie et al. (2000)], these and other studies suggest essential roles for CaN, PP-1, and GluR1 PKA-dephosphorylation in regulation of AMPA receptor trafficking in cultured neurons and LTD in hippocampus (Ehlers, 2000; Lee et al., 2000; Morishita et al., 2001). However, additional recent studies have shown that regulatory interactions of GluR2 subunits with scaffold and secretory proteins, which are not likely to involve AKAP79/150, are also important for regulating AMPA receptor trafficking in cultured neurons and during LTD (Luthi et al., 1999; Chung et al., 2000; Daw et al., 2000; Osten et al., 2000). Nonetheless, endocytosis of AMPA receptors containing GluR1 and GluR2 subunits requires CaN activity (Ehlers, 2000; Lin et al., 2000). Thus, our findings for NMDA receptor-triggered removal of the AKAP79/150-PKA complex from synapses fit nicely with these observations by showing coordination of PKA and $\mathrm{CaN}$ signaling events that may regulate both AMPA receptor dephosphorylation and localization. Importantly, our results show that $\mathrm{CaN}$ may function in a novel manner to regulate PKA signaling through controlling synaptic localization of a common anchoring protein, AKAP79/150. In the future it will interesting to investigate further how interactions of AKAP79/150 with F-actin, PI-4,5- $\mathrm{P}_{2}, \mathrm{CaM}$, and anchored $\mathrm{CaN}$ and PKA fit into these complex signaling pathways controlling the actin cytoskeleton and AMPA receptors in synaptic plasticity.

\section{REFERENCES}

Aderem A (1992) The MARCKS brothers: a family of protein kinase C substrates. Cell 71:713-716.

Allison DW, Gelfand VI, Spector I, Craig AM (1998) Role of actin in anchoring postsynaptic receptors in cultured hippocampal neurons: differential attachment of NMDA versus AMPA receptors. J Neurosci 18:2423-2436.

Allison DW, Chervin AS, Gelfand VI, Craig AM (2000) Postsynaptic scaffolds of excitatory and inhibitory synapses in hippocampal neurons: maintenance of core components independent of actin filaments and microtubules. J Neurosci 30:4545-4554.

Barria A, Muller D, Derkach V, Griffith LC, Soderling TR (1997) Regulatory phosphorylation of AMPA-type glutamate receptors by CaM-KII during long-term potentiation. Science 276:2042-2045.

Beattie EC, Carroll RC, Yu X, Morishita W, Yasuda H, von Zastrow M, Malenka RC (2000) Regulation of AMPA receptor endocytosis by a signaling mechanism shared with LTD. Nat Neurosci 3:1291-1300.

Blitzer RD, Connor JH, Brown GP, Wong T, Shenolikar S, Iynegar R, Landau EM (1998) Gating of CaMKII by cAMP-regulated protein phosphatase activity during LTP. Science 280:1940-1942.

Bregman DB, Bhattacharyya N, Rubin CS (1989) High affinity binding protein for the regulatory subunit of $\mathrm{cAMP}$-dependent kinase II $\beta$ : cloning, characterization and expression of cDNAs for rat brain P150. J Biol Chem 264:4648-4656.

Bubb MR, Lenox RH, Edison AS (1999) Phosphorylation-dependent conformational changes induce a switch in the actin-binding function of MARCKS. J Biol Chem 274:36472-36478.

Carr DW, Stofko-Hahn RE, Fraser IDC, Cone RD, Scott JD (1992) Localization of the cAMP-dependent protein kinase to the postsynaptic densities by A-kinase anchoring proteins: characterization of AKAP79. J Biol Chem 267:16816-16823.

Carroll RC, Lissin DV, von Zastrow M, Nicoll RA, Malenka RC (1999a) Rapid redistribution of glutamate receptors contributes to long-term depression in hippocampal cultures. Nat Neurosci 2:454-460.

Carroll RC, Beattie EC, Luscher C, Altschuler Y, Nicoll RA, Malenka RC, Von Zastrow M (1999b) Dynamin-dependent endocytosis of ionotropic glutamate receptors. Proc Natl Acad Sci USA 96:14112-14117.

Carroll RC, Beattie EC, von Zastrow M, Malenka RC (2001) Role of AMPA receptor endocytosis in synaptic plasticity. Nat Rev Neurosci $2: 315-324$

Chen L, Chetkovich DM, Petrailia R, Sweenet N, Kawaski Y, Wenthold R, Bredt DS, Nicoll RA (2000) Stargazin mediates synaptic targeting of AMPA receptors by two distinct mechanisms. Nature 408:936-943.

Chung HJ, Xia J, Scannevin RH, Zhang X, Huganir RL (2000) Phosphorylation of the AMPA receptor subunit GluR2 differentially regulates its interaction with PDZ domain-containing proteins. J Neurosci 20:7258-7267.

Coghlan VM, Perrino BA, Howard M, Langeberg LK, Hicks JB, Gallatin
WM, Scott JD (1995) Association of protein kinase A and protein phosphatase 2B with a common anchoring protein. Science 267:108-112. Colledge M, Dean RA, Scott GK, Langeberg LK, Huganir RL, Scott JD (2000) Targeting of PKA to glutamate receptors through a MAGUKAKAP complex. Neuron 27:107-119.

Craven SE, Bredt DS (2000) Synaptic targeting of the postsynaptic density protein PSD-95 mediated by a tyrosine-based trafficking signal. J Biol Chem 275:20045-20051.

Dell'Acqua ML, Faux MC, Thorburn J, Thorburn A, Scott JD (1998) Membrane targeting sequences on AKAP79 bind phosphatidylinositol-4 5-bisphosphate. EMBO J 17:2246-2260.

Daw MI, Chittajallu R, Bortolotto ZA, Dev KK, Duprat F, Henely JM, Collingridge GL, Isaac JTR (2000) PDZ proteins interacting with C-terminal GluR2/3 are involved in a PKC-dependent regulation of AMPA receptors at hippocampal synapses. Neuron 28:873-886.

El-Husseini AE, Craven SE, Chetkovich DM, Fierstein BL, Schnell E, Aoki C, Bredt DS (2000a) Dual palmitoylation of PSD-95 mediates its vesiculotubular sorting, postsynaptic targeting, and ion channel clustering. J Cell Biol 148:159-171.

El-Husseini AE, Craven SE, Chetkovich DM, Nicoll RA, Bredt DS (2000b) PSD-95 involvement in maturation of excitatory synapses. Science 290:1364-1368.

Ehlers MD (2000) Reinsertion and degradation of AMPA receptors determined by activity-dependent endocytic sorting. Neuron 28:511-525.

Faux MC, Scott JD (1997) Regulation of the AKAP79-protein kinase C interaction by $\mathrm{Ca}^{2+}$ /calmodulin. J Biol Chem 272:17038-17044.

Goslin K, Asmussen H, Banker G (1998) Rat hippocampal neurons in low density culture In: Culturing nerve cells, Ed 2 (Banker G, Goslin K, eds), pp 339-370. Cambridge, MA: MIT.

Halpain S, Hipolito A, Saffer L (1998) Regulation of F-actin stability in dendritic spines by glutamate receptors and calcineurin. J Neurosci 18:9835-9844.

Hausken ZE, Dell'Acqua ML, Coghlan VM, Scott JD (1996) Mutational analysis of the A-kinase anchoring protein (AKAP)-binding site on RII: classification of side chain determinants for anchoring and isoform seective association with AKAPs. J Biol Chem 271:29016-29022.

Hayashi Y, Shi S-H, Esteban JA, Piccini A, Poncer J-C, Malinow R (2000) Driving AMPA receptors to synapses by LTP and CaMKII: requirement for GluR1 and PDZ domain interaction. Science 287:2262-2267.

Kashishian A, Howard M, Loh C, Gallatin M, Hoekstra MF, Lai Y (1998) AKAP79 inhibits calcineurin through a site distinct from the immunophilin-binding region. J Biol Chem 273:27412-27419.

Kennedy MB (1997) The postsynaptic density at glutamatergic synapses. Trends Neurosci 20:264-268.

Kim C-H, Lisman JE (1999) A role of actin filament in synaptic transmission and long-term potentiation. J Neurosci 19:4314-4324.

Krucker T, Siggins GR, Halpain S (2000) Dynamic actin filaments are required for stable long-term potentiation (LTP) in area CA1 of the hippocampus. Proc Natl Acad Sci USA 97:6856-6861.

Lai MM, Hong JJ, Ruggiero AM, Burnett PE, Slepnev VI, De Camilli P, Snyder SH (1999) The calcineurin-dynamin 1 complex as a calcium sensor for synaptic vesicle endocytosis. J Biol Chem 274:25963-25966.

Lee H-K, Kameyama K, Huganir RL, Bear MF (1998) NMDA induces long-term synaptic depression and dephosphorylation of AMPA receptors in hippocampus. Neuron 21:1151-1162.

Lee H-K, Barbarosie M, Kameyama K, Bear MF, Huganir RL (2000) Regulation of AMPA receptor phosphorylation sites during bidirectional synaptic plasticity. Nature 405:955-959.

Leonard AS, Davare MA, Horne MC, Garner CC, Hell JW (1998) SAP97 is associated with the alpha-amino-3-hydroxy-5-methylisoxazole4-propionic acid receptor GluR1 subunit. J Biol Chem 273:19518-19524

Li Y, Ndubuka C, Rubin CS (1996) A kinase anchor protein 75 targets regulatory subunits of cAMP-dependent protein kinase II to the cortica actin cytoskeleton in non-neuronal cells. J Biol Chem 271:16862-16869.

Lin JW, Ju W, Foster K, Lee SH, Ahmadian G, Wyszynski M, Wang YT, Sheng M (2000) Distinct molecular mechanisms and divergent endocytic pathways of AMPA receptor internalization. Nat Neurosci 3:1282-1290.

Lissin DV, Carroll RC, Nicoll RA, Malenka RC, von Zastrow M (1999) Rapid, activation-induced redistribution of ionotropic glutamate receptors in cultured hippocampal neurons. J Neurosci 19:1263-1272.

Lue RA, Marfatia SM, Branton D, Chisti AH (1994) Cloning and characterization of hldg: the human homologue of the Drosophila discs large tumor suppressor binds to protein 4.1. Proc Natl Acad Sci USA 91:9818-9822.

Lue RA, Brandin E, Chan EP, Branton D (1996) Two independent domains of hDlg are sufficient for subcellular targeting: the PDZ1-2 conformational unit and an alternatively spliced domain. J Cell Biol 135:1125-1137.

Luscher C, Nicoll RA, Malenka RC, Muller D (2000) Synaptic plasticity and dynamic modulation of the postsynaptic membrane. Nat Neurosci 3:545-550.

Luthi A, Chittajallu R, Duprat F, Palmer MJ, Benke TA, Kidd FL, Henley JM, Isaac JTR, Collingridge GL (1999) Hippocampal LTD 
expression involves a pool of AMPARs regulated by the NSF-GluR2 interaction. Neuron 24:389-399.

Man H-Y, Lin JW, Ju WH, Ahmadian G, Liu L, Becker LE, Sheng M, Wang YT (2000) Regulation of AMPA receptor-mediated synaptic transmission by clathrin-dependent receptor internalization. Neuron 25:649-662.

Migaud M, Charlesworth P, Dempster M, Webster LC, Watabe AM, Makhinson M, He Y, Ramsay MF, Morris RGM, Morrison JH, O’Dell TJ, Grant SGN (1998) Enhanced long-term potentiation and impaired learning in mice with mutant postsynaptic density-95 protein. Nature 396:433-439

Morishita W, Connor JH, Xia H, Quinlan M, Shenolikar S, Malenka RC (2001) Regulation of synaptic strength by protein phosphatase 1 . Neuron 32:1133-1148.

Mulkey RM, Endo S, Shenolikar S, Malenka RC (1994) Involvement of a calcineurin/inhibitor-1 phosphatase cascade in hippocampal longterm depression. Nature 369:486-488.

Okabe S, Miwa A, Okado H (2001) Spine formation and correlated assembly of presynaptic and postsynaptic molecules. J Neurosci 21:6105-6114.

Osten P, Khatri L, Perez JL, Kohr G, Giese G, Daly C, Schulz TW, Wensky A, Lee LM, Ziff EB (2000) Mutagenesis reveals a role for ABP/GRIP binding to GluR2 in synaptic surface accumulation of the AMPA receptor. Neuron 27:313-325.

Passafaro M, Piech V, Sheng M (2001) Subunit-specific temporal and spatial patterns of AMPA receptor exocytosis in hippocampal neurons. Nat Neurosci 8:917-926.

Pickard L, Noel J, Henley JM, Collingridge GL, Molnar E (2000) Developmental changes in synaptic AMPA and NMDA receptor distribution and AMPA receptor subunit composition in living hippocampal neurons. J Neurosci 20:7922-7931.

Rao A, Kim E, Sheng M, Craig AM (1998) Heterogeneity in the molecular composition of excitatory postsynaptic sites during development of hippocampal neurons in culture. J Neurosci 18:1217-1229.

Rosenmund C, Carr DW, Bergeson SE, Nilaver G, Scott JD, Westbrook GL (1994) Anchoring of protein kinase A is required for modulation of AMPA/kainate receptors on hippocampal neurons. Nature 368:853-856.

Sans N, Racca C, Petralia RS, Wang Y-X, McCallum J, Wenthold RJ (2001) Synapse-associated protein 97 selectively associates with a sub- set of AMPA receptors early in their biosynthetic pathway. J Neurosci 21:7506-7516.

Shen L, Liang F, Walensky LD, Huganir RL (2000) Regulation of AMPA receptor GluR1 subunit surface expression by a $4.1 \mathrm{~N}$-linked actin cytoskeletal association. J Neurosci 20:7932-7940.

Sheng M, Lee SH (2001) AMPA receptor trafficking and the control of synaptic transmission. Cell 105:825-828.

Sheng M, Scala C (2001) PDZ domains and the organization of supramolecular complexes. Annu Rev Neurosci 24:1-29.

Shi S-H, Hayashi Y, Petralia RS, Zaman S, Wenthold RJ, Svoboda K, Malinow R (1999) Rapid spine delivery and redistribution of AMPA receptors after synaptic NMDA receptor activation. Science 284:1811-1816.

Shi S-H, Hayashi H, Esteban JA, Malinow R (2001) Subunit-specific rules governing AMPA receptor trafficking to synapses in hippocampal pyramidal neurons. Cell 105:331-343.

Tall EG, Spector I, Pentyala SN, Bitter I, Rebecchi MJ (2000) Dynamics of phosphatidylinositol 4, 5-bisphosphate in actin-rich structures. Curr Biol 10:743-746.

Tavalin SJ, Colledge MC, Hell JW, Langeberg LK, Huganir RL, Scott JD (2002) Regulation of GluR1 by the A-kinase anchoring protein 79 (AKAP79) signaling complex shares properties with long-term depression. J Neurosci 22:3044-3051.

Tomita S, Nicoll RA, Bredt DS (2001) PDZ protein interactions regulating glutamate receptor function and plasticity. J Cell Biol 153:F19-F23.

Tsien RY (1998) Green fluorescent protein. Annu Rev Biochem 67:509-544.

Wang J, Arbuzova A, Hangyas-Mihalyne G, McLaughlin S (2001) The effector domain of myristoylated alanine-rich $\mathrm{C}$ kinase substrate binds strongly to phosphatidylinositol 4, 5-bisphosphate. J Biol Chem 276:5012-5019.

Wu H, Reuver SM, Kuhlendahl S, Chung WJ, Garner CC (1998) Subcellular targeting and cytoskeletal attachment of SAP97 to the epithelial lateral membrane. J Cell Sci 111:2365-2376.

Ziff EB (1997) Enlightening the postsynaptic density. Neuron 19:11631174.

Zhang W, Benson DL (2001) Stages of synapse development defined by dependence on F-actin. J Neurosci 21:5169-5181.

Zhou Q, Xiao M-Y, Nicoll RA (2001) Contribution of cytoskeleton to the internalization of AMPA receptors. Proc Natl Acad Sci USA 98:1261-1266. 